\title{
On the impacts of phytoplankton-derived organic matter on the properties of the primary marine aerosol - Part 1: Source fluxes
}

\author{
E. Fuentes ${ }^{1}$, H. Coe ${ }^{1}$, D. Green ${ }^{2}$, G. de Leeuw ${ }^{3,4,5}$, and G. McFiggans ${ }^{1}$ \\ ${ }^{1}$ Centre for Atmospheric Sciences, School of Earth, Atmospheric and Environmental Sciences, Manchester M13 9PL, UK \\ ${ }^{2}$ Scottish Association for Marine Science, Oban, UK \\ ${ }^{3}$ Finnish Meteorological Institute, Climate Change Unit, Helsinki, Finland \\ ${ }^{4}$ University of Helsinki, Department of Physics, Helsinki, Finland \\ ${ }^{5}$ TNO, Environment, Health and Safety, Utrecht, The Netherlands
}

Received: 15 March 2010 - Published in Atmos. Chem. Phys. Discuss.: 8 June 2010

Revised: 24 September 2010 - Accepted: 29 September 2010 - Published: 1 October 2010

\begin{abstract}
The effect of biogenic dissolved and colloidal organic matter on the production of submicron primary seaspray aerosol was investigated via the simulation of bubble bursting in seawater enriched with phytoplankton-released organics.

Seawater samples collected along a transect off the West African coast during the RHaMBLe cruise (RRS Discovery cruise D319), conducted as part of the SOLAS UK program, were analysed in order to identify the dominant oceanic algal species in a region of high biological activity. Cultures of microalgal strains representative of the species found in the collected seawater were grown in order to produce natural bioexudate. Colloidal plus dissolved organic fraction in this material remaining after $<0.2 \mu \mathrm{m}$ filtration was employed to prepare organic-enriched seawater proxies for the laboratory production of marine aerosol using a plungingwaterjet system as an aerosol generator. Submicron size distributions of aerosols generated from different organic monolayers and seawater proxies enriched with biogenic exudate were measured and compared with blanks performed with artificial seawater devoid of marine organics. A shift of the aerosol submicron size distribution toward smaller sizes and an increase in the production of particles with dry diameter $\left(D_{p 0}\right)<100 \mathrm{~nm}$ was repeatedly observed with increasing amounts of diatomaceous bioexudate in the seawater proxies used for aerosol generation. The effect was found to be sensitive to the organic carbon concentration in seawa-
\end{abstract}

Correspondence to: G. McFiggans (g.mcfiggans@manchester.ac.uk) ter and the algal exudate type. Diatomaceous exudate with organic carbon concentration $\left(\mathrm{OC}_{<0.2 \mu \mathrm{m}}\right)>175 \mu \mathrm{M}$ was required to observe a significant impact on the size distribution, which implies that effects are expected to be substantial only in high biological activity areas abundant with diatom algal populations. The laboratory findings were in agreement with analogous bubble-bursting experiments conducted with unfiltered oceanic seawater collected during the RHaMBLe cruise, which revealed a higher production of particles with $D_{p 0}<100 \mathrm{~nm}$ at regions with high biological activity. These findings suggest that the increase in the atmospheric aerosol modal sizes from winter to summer, reported by long-term observations in North Atlantic waters, is not directly due to an impact of the higher primary organic matter production occurring during warm periods.

A novel sub-micrometric size-resolved source flux function, explicitly defined as a function of the diatomaceous exudate concentration, was derived from the size distribution measurements and the estimation of the fractional whitecap coverage. According to the defined parameterisation, a $300 \mu \mathrm{M} \mathrm{OC}<0.2 \mu \mathrm{m}$ concentration of diatomaceous exudate in seawater produces an overall increment in the total source particle flux of $\sim 20 \%$ with respect to the organics-free seawater case. The effect increases with decreasing particle size for $D_{p 0}<100 \mathrm{~nm}$, resulting in multiplicative factors between $1.02-2$ with respect to the particle flux generated from seawater devoid of marine organics. The total source flux derived from the presented parameterisation was compared to recent definitions of sea-spray source fluxes based on laboratory and field observations in the literature.

Published by Copernicus Publications on behalf of the European Geosciences Union. 


\section{Introduction}

The marine aerosol constitutes an important fraction of the global natural aerosol flux. As a consequence, it significantly contributes to the Earth's radiative budget, atmospheric albedo and biogeochemical processes (O'Dowd et al., 2004; O'Dowd and de Leeuw, 2007). Marine aerosols can affect the atmospheric radiative balance both directly by scattering and absorbing solar radiation and indirectly by modifying the microphysics, radiative properties, and lifetime of clouds (Murphy et al., 1998). It has been postulated that the sea-spray production would be involved in a cloudclimate feedback process if the increment of wind speed as a result of global warming on oceanic regions would lead to an increase in the sea-spray particle production (Latham and Smith, 1990).

Sea spray primary particles are produced as a result of breaking wave processes occurring on oceans surfaces. Wind generated waves breaking at wind speeds higher than $4 \mathrm{~ms}^{-1}$ produce sea-spray droplets with sizes from $\leq 0.01 \mu \mathrm{m}$ to $\geq 25 \mu \mathrm{m}$ (Clarke et al., 2006; Lewis and Schwartz, 2004). Breaking waves dissipate up to $40 \%$ of their energy and up to $50 \%$ of the energy loss is expended in entraining air in the water bulk and creating a dense plume of bubbles (Rapp and Melville, 1990). The bubbles formed rise and burst upon reaching the surface, thereby producing the so-called film and jet drops. The sea spray total number concentration is normally dominated by particles in the submicron size range from 5 to $300 \mathrm{~nm}$, with a decline in the particle number with increasing size (Fitzgerald, 1991).

Atmospheric marine aerosols consist of primary aerosol, which comprises organic material and sea-salt and is produced on the ocean surface by bubble-bursting and tearing from breaking waves (Anguelova and Webster, 1999), and secondary aerosol, formed by non sea-salt sulphate and organic species originated via gas-to-particle conversion processes such as homogeneous nucleation and condensation onto pre-existing particles (O'Dowd et al., 1997). Chemical analysis of atmospheric sea-spray particles collected in field experiments has provided evidence for the presence of significant concentrations of organic matter in the submicron size range (Hoffman and Duce, 1977; Novakov et al., 1997; Middlebrook et al., 1998; Putaud et al., 2000; Cavalli et al., 2004). The contribution of the organic fraction in the marine aerosol has been found to be seasonal, accounting for up to $63 \%$ of the submicrometre aerosol dry mass, with an increasing enrichment with decreasing particle size (O'Dowd et al., 2004; Yoon et al., 2007). Studies on North East Atlantic marine aerosol conducted over long periods (O'Dowd et al., 2004; Yoon et al., 2007) have shown that the shape of the submicron sea spray distribution presents a seasonal pattern, characterized by an increase of the accumulation and Aitken modes modal sizes from winter to summer. Although this finding has been attributed to an effect produced by pri- mary organic matter released by marine biota (O'Dowd et al., 2004) little is known on the influence of these organics on the production and the behaviour of the marine aerosol.

Bubble bursting experiments with seawater have shown high organic mass fractions in the primary aerosol submicron size region (Keene et al., 2007; Facchini et al., 2008). The submicron organic matter was found to be almost entirely water insoluble and consisted of colloids and aggregates exuded by phytoplankton (Facchini et al., 2008). The distribution of the insoluble organic matter and sea-salt content in the submicron size range observed in bubble bursting experiments was similar to that measured in atmospheric marine aerosol samples collected during periods of high biological activity (O'Dowd et al., 2004; Facchini et al., 2008).

Under breaking wave conditions, the primary mechanism of transport of biological surfactants to the ocean surface is by bubble scavenging. When the bubbles reach the water surface, the organics absorbed on their surface are ejected into the atmosphere along with dissolved inorganic constituents of seawater. Thereby, the seawater composition, bubble spectrum, bubble hydrodynamics and the formation and chemical composition of the aerosol are closely interrelated and interdependent (Duce and Hoffman, 1976; Tseng et al., 1992).

The generation of sea-spray particles by bubble bursting has been simulated in the laboratory in order to study the primary aerosol production. Mårtensson et al. (2003) and Tyree et al. (2007) conducted aerosol size distribution measurements by bubbling artificial seawater through different porous media. Sellegri et al. (2006) compared the bubble spectrum and the submicron aerosol size distributions generated by bubble bursting using a water recirculation system and aeration through glass frits of different porosity. Some of these investigations also studied the effect of salinity, water temperature (Mårtensson et al., 2003; Tyree et al., 2007; Sellegri et al., 2006) and organic matter by using organic proxies, such as oleic acid (Tyree et al., 2007) and sodium dodecyl sulphate (SDS) (Sellegri et al., 2006). The study of the effect of surfactants on the size distribution performed by Sellegri et al. (2006) and Tyree et al. (2007) indicated a shift of the distributions toward smaller sizes with respect to the baseline case without organic surrogate. Tyree et al. (2007) reported that this effect was accompanied by an increase in the particle production at constant temperature with respect to the experiment without surfactants. The chemical composition of the phytoplankton-released organic matter consists of a complex mixture of dissolved and particulate species, including a variety of organic compounds such as carboxylic acids, lipids, amino acids and carbohydrates (Aluwihare and Repeta, 1999). Considering that the organic enrichment of particles produced by bubble bursting is dependent on the type of organic compound in the water medium (Tseng et al., 1992), it is uncertain whether compound models such as SDS and oleic acid are representative of the behaviour of the complex mixtures of organics comprising the marine bioexudates. Thereby, the use of proxies chemically representative 
of primary marine organic matter would be more appropriate for these type of studies.

Another important aspect for laboratory studies on seaspray aerosol is the reproduction of the real process through which marine particles are generated (Fuentes et al., 2010). It is a common practice to use atomizers for the generation of laboratory marine aerosol proxies from seawater samples (McNeill et al., 2006; Abo Riziq et al., 2007; Saul et al., 2006; Svenningsson et al., 2006; Braban et al., 2007; Niedermeier et al., 2007; Taketani et al., 2009), while only in a few studies has the aerosol been produced by bubble bursting via aeration through glass frits or diffusers (Cloke et al., 1991; Mårtensson et al., 2003; Keene et al., 2007; Tyree et al., 2007; Wise et al., 2009) or using water jets (Cipriano and Blanchard, 1981; Sellegri et al., 2006; Facchini et al., 2008; Hultin et al., 2009). Comparative analysis on the performance of different aerosol generators has shown that the mechanism of particle production can affect the particle size distribution and the behaviour of the laboratory-generated marine aerosol (Fuentes et al., 2010). The spectrum of bubbles generated by water impingement with plunging water jet generators has been shown to resemble the oceanic bubble spectrum shape (Sellegri et al., 2006; Hultin et al., 2009; Fuentes et al., 2010). It is expected that this type of system, which simulate the physics of bubble formation by water impingement, is able to produce particles more representative of the primary marine aerosol than other available generation systems (Fuentes et al., 2010).

Estimates of sea-spray source fluxes have frequently used the function derived by Monahan et al. (1986), which although derived and defined for the $0.8-10 \mu \mathrm{m}$ dry diameter range, is usually also applied to the submicron size region. In an attempt to provide more reliable source functions in the submicron range, size-resolved parameterisations derived from field and laboratory measurements have recently been proposed (Mårtensson et al., 2003; Clarke et al., 2006; Tyree et al., 2007). Formulations of net and source fluxes as a function of the wind speed in the submicron range have been derived from eddy covariance aerosol flux measurements by Nilsson et al. (2001) and Geever et al. (2005) in Artic and North Atlantic waters, respectively. Due to the lack of understanding on the effect of organics of biogenic origin on the production of sea-spray, this factor has not generally been included in the definition of marine aerosol fluxes. To address this gap, recently, O'Dowd et al. (2008) developed an inorganic-organic submicron sea-spray source function based on the parameterisation of the particles organic fraction as a function of the seawater chlorophyll- $a$ concentration obtained from satellite images. In their approach, the derived fractional composition as a function of the chlorophyll$a$ field was integrated into a power-law number flux function derived from data of Geever et al. (2005), while the sea-spray diameter seasonal variation was determined from Yoon et al. (2007). In addition to this approach, Ceburnis et al. (2008) presented net seaspray flux data as a function of the wind speed, including organic compounds in their analysis.

Photographic observation of bursting bubbles has shown that the bubble-bursting process can be significantly altered by the addition of surfactants, which particularly affects the height and width of the bursting jet formed and the number and size of drops released (Boulton-Stone, 1995; Dey et al., 1997). Considering these effects, it is reasonable to assume that the presence of surface-active matter released by biota in seawater might have an effect on the primary aerosol production through the impact of these natural surfactants on the bubble-bursting process.

This study aims to elucidate the extent to which the organics produced by marine phytoplankton can affect the particle size distribution and the production of primary marine aerosol. Seawater samples were collected along a transect off the West African coast during the UK SOLAS funded Reactive Halogens in the Marine Boundary Layer (RHaMBLe) cruise in order to identify the main algal species in a region of high biological activity. Cultures of microalgal strains representative of species found in the collected seawater were grown in order to produce natural bioexudate. This material was used to prepare organic-enriched seawater proxies for the laboratory production of marine aerosol using a plunging-waterjet system as the aerosol generator. Measurements of the size distribution of the aerosols generated from seawater proxies enriched with algal exudate were conducted and compared with blanks performed with artificial seawater devoid of marine surfactants. A novel size-resolved source flux function including a term to account for the seawater organic concentration was derived from the size distribution measurements by applying the whitecap method. The total source flux inferred from the presented parameterisation was compared to recent definitions of sea-spray source fluxes based on laboratory and field observations in the literature.

\section{Algal species in high biological activity regions: RHaMBLe cruise}

Seawater samples were collected along a transect off the West African coast on board the British research vessel RRS Discovery (D319, RHaMBLe cruise), conducted as part of the SOLAS UK program (Lee et al., 2010), in order to identify the dominant oceanic algal species in the high biological activity region located at the vicinity of Cape Verde islands. The cruise mobilised from Lisbon (Portugal) on 19 May and docked in Falmouth (UK) on 11 June 2007.

Figure 1 shows the cruise track overlaid onto remotelysensed chlorophyll- $a$ surface concentration retrieved from SeaWiffs satellite data averaged across the period that the ship was in the region, along with the positions where seawater samples were collected for analysis. The on-board seawater collection system consisted of a torpedo-shaped towfish immersed at a constant depth of 1-2 $\mathrm{m}$ and a peristaltic pump 


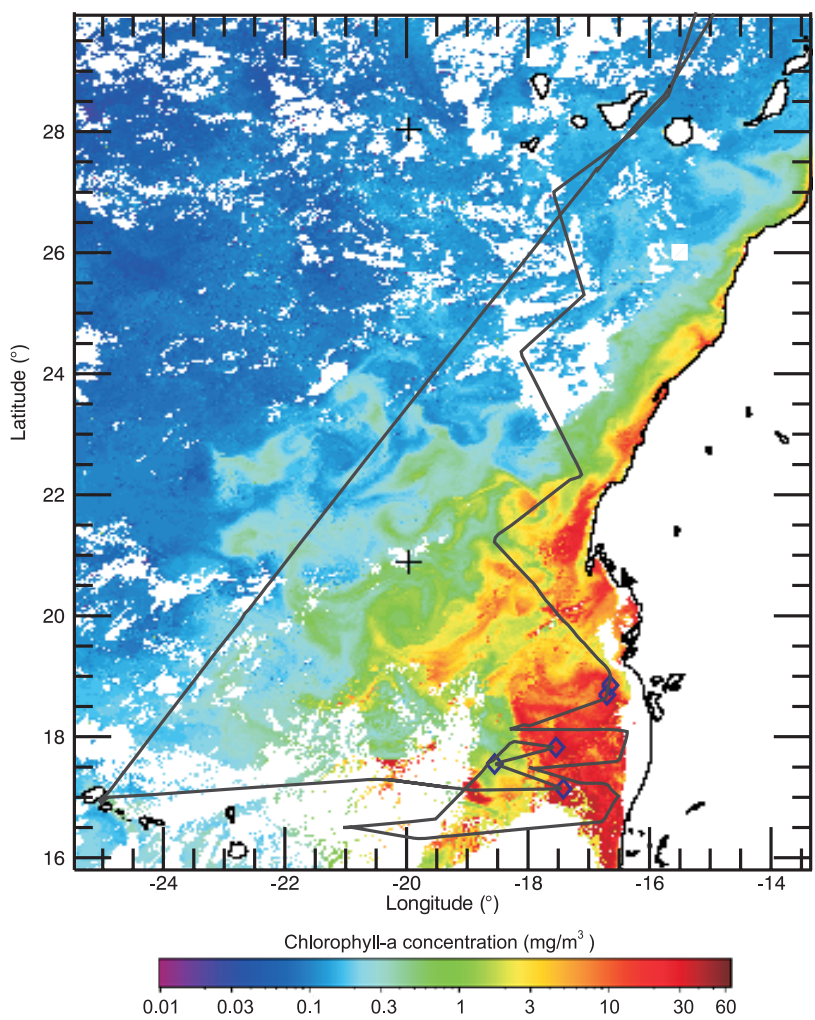

Fig. 1. RHaMBLe cruise track off the West coast of Africa overlaid on satellite chlorophyll image (SeaWiffs Ocean Color data) averaged over the cruise period on May-June 2007. Blue marks indicate the points at which seawater samples were collected for algal species identification.

system, which provided seawater to the on-board collection points.

\subsection{Methods}

\subsubsection{Seawater collection and pre-treatment}

The collected samples were analysed for chlorophyll- $a$, organic carbon content and taxonomic identification of the main algal species. For chlorophyll- $a$ analysis, seawater samples of $600-3000 \mathrm{~mL}$ were filtered through a $25 \mathrm{~mm}$ diameter glass fiber filter (GF/F Whatman), which was immediately stored at a temperature below $-20^{\circ} \mathrm{C}$. For algal identification seawater samples were split into two $500 \mathrm{~mL}$ brown polypropylene bottles. In order to preserve the algal specimens the samples were fixed with Lugol's iodine (for diatom and dinoflagellates preservation) and Glutaraldehyde solution (for cyanobacteria, bacteria and nanoplankton preservation) to final concentrations of $1 \%$, and stored at 4 $8^{\circ} \mathrm{C}$ in the dark.

\subsubsection{Seawater analysis methods}

For analysis of the organic carbon content, the cell biomass was removed by filtration through pre-combusted $\left(450{ }^{\circ} \mathrm{C}\right.$ for $8 \mathrm{~h})$ glass fiber filters (GF/F; Whatman) and subsequently through deionised-water rinsed and sterile polycarbonate filters $(0.2 \mu \mathrm{m}$; Millipore). The seawater samples were aspirated from the filtrate using acid-washed glass pipettes to precombusted glass ampules or autosampler bottles and acidified with orthophosphoric acid and stored in the dark at $4{ }^{\circ} \mathrm{C}$ until analysis. Organic carbon analyses were conducted as per standard procedures on a Shimadzu TOC-V CPH/CPN instrument (Alvarez-Salgado and Miller, 1998).

Chlorophyll- $a$ was extracted using $90 \%$ acetone and the concentration determined by fluorometry using a Turner Designs Trilogy fluorometer, as per standard procedures (Parsons et al., 1984). A calibration curve was run alongside of these measurements and the fluorescence from the unknown samples was extrapolated from the standard curve. The raw chlorophyll- $a$ concentrations were corrected for the volume of sample filtered.

Bacteria, cyanobacteria, heterotrophic- and photosynthetic-nanoflagellates were enumerated and classified into broad groups by filtering between $5-15 \mathrm{~mL}$ of the glutaraldehyde fixed sample. The filters were stained as appropriate, and up to 50 fields of view were counted by epifluorescence microscopy. Counts were back calculated to give the abundance of each cell type per litre. Diatom and dinoflagellates species fixed in Lugol's iodine were enumerated by settling $50 \mathrm{~mL}$ of the sample and counting a range of fields of view (dependent on cell density). Counts were back-calibrated based on the number of fields of view and the volume filtered to give an abundance of each cell type per litre.

\subsection{Results of RHaMBLe seawater samples analysis}

Figures 2-5 show a summary of the results from the chlorophyll- $a$ and algal identification analysis conducted on the seawater collected during the RHaMBLe cruise. Results in Fig. 2 and Table 1 indicate that the phytoplankton population in the region was very high, with nanoflagellates (HNAN and PNAN) as the dominant group, followed by diatoms and dinoflagellates, respectively. The high biological activity in the area is also indicated by the chlorophyll- $a$ concentration in seawater. Table 1 presents a summary of the properties of the seawater samples collected during the cruise. Figure 2 (right) indicates that the chlorophyll- $a$ concentration correlates with increased numbers of PNAN, diatoms and dinoflagellates cells, while the cyanobacteria and HNAN populations decrease with increasing chlorophyll- $a$.

The abundant nanoflagellate group (Fig. 3) is dominated by photosynthetic nanoplankton (PNAN), in which Chrysochromulina spp. and Phaeocystis spp. are the most prevalent species. A wide variety of diatom and 
Table 1. Summary of chlorophyll- $a, \mathrm{OC}_{<0.2 \mu \mathrm{m}}$ concentration and cell count analysis of oceanic seawater collected during the RHaMBLe cruise in the high biological activity region near Cape Verde Islands (May-June 2007).

\begin{tabular}{lrrrrrr}
\hline & $\begin{array}{r}\text { Chl- } a \\
(\mu \mathrm{g} / \mathrm{L})\end{array}$ & $\begin{array}{r}\mathrm{OC}_{<0.2 \mu \mathrm{m}} \\
(\mu \mathrm{M})\end{array}$ & $\begin{array}{r}\text { HNAN No. } \\
(\text { cells/L) }\end{array}$ & $\begin{array}{r}\text { PNAN No. } \\
(\text { cells/L) }\end{array}$ & $\begin{array}{r}\text { Diatoms No. } \\
(\text { cells/L) }\end{array}$ & $\begin{array}{r}\text { Dinoflagellates No. } \\
(\text { cells/L) }\end{array}$ \\
\hline Minimum & 0.81 & 92 & $6.21 \mathrm{E}+06$ & $2.79 \mathrm{E}+07$ & 570 & 60 \\
Maximum & 4.69 & 451 & $3.15 \mathrm{E}+07$ & $2.55 \mathrm{E}+08$ & $3.23 \mathrm{E}+6$ & 2100 \\
Average & 1.9 & 282 & $1.62 \mathrm{E}+07$ & $1.37 \mathrm{E}+08$ & $7.08 \mathrm{E}+5$ & 830 \\
\hline
\end{tabular}

dinoflagellate taxa (19 species and 16 species, respectively) were identified in the collected waters (Figs. 4 and 5). Normalization of the total cell counts (Fig. 4, right) indicates that the dominant strain in the diatom population is the Thalassiosira species in the first two samples while after 28 May 12:00 the most abundant algal specie found was Ps. nitzschia cf. delicatissima, which accounted for 48 to $96 \%$ of the total cell concentration. The variability between different days indicates that the distribution of algal species in the seawater was dependent on the spatial and time coordinates. Likewise, the analysis on dinoflagellates (Fig. 5) shows spatial and time variations, characterised by a distribution of 8 taxa accounting for $5-20 \%$ of the total cell count in the 27 May and 28 May 12:00 samples, while populations dominated by Prorocentrum species are found in the 28 May 07:15 and 1 June samples. It is also noticeable that the Prorocentrum triestinum species were present in all the samples, comprising $\sim 18-78 \%$ of the total dinoflagellate counts.

\section{Laboratory aerosol experiments}

\subsection{Sample preparation}

Artificial seawater was prepared from analytical grade salts and deionised water following the method described by Kester (1967), so that the ionic mass ratios of $\mathrm{Na}^{+}, \mathrm{Cl}^{-}$, $\mathrm{Mg}^{2+}, \mathrm{HCO}_{3}^{-}$and $\mathrm{SO}_{4}^{2-}$ were comparable to those in seawater. Seawater samples of $35 \%$ salinity were prepared by adjusting the solution density at the given temperature using a hydrometer.

Natural seawater samples collected from North Atlantic waters were enriched with biogenically-synthesized organic matter by culturing algal cells in the laboratory, after removal of natural organic material. Cultures of diatoms and nanoplankton, which were the most abundant algal groups identified in the RHaMBLe cruise seawater samples, were grown to produce bioexudate. The seawater used for growing the algal cultures was collected near the Scotland coast (UK) (Tiree passage, $56^{\circ} 37.7^{\prime} \mathrm{N}, 6^{\circ} 23.8^{\prime} \mathrm{W}$ ) by pumping surface water from $\sim 5 \mathrm{~m}$ depth into $20 \mathrm{~L}$ carbouys. After collection, the seawater was aged prior to use. The aged natural seawater was filtered (GF/F; Whatman) to remove algal and bacterial biomass. The sample was subsequently amended with a $f / 2$ nutrients solution and either selenite or silicate (Guillard, 1975), and sterilised by autoclaving $\left(121^{\circ} \mathrm{C}\right.$ for $15 \mathrm{~min}$ ) in order to prepare the medium for the algal culture. The algal cultures were grown in glass Erlenmeyer flasks fitted with gas permeable stoppers or $20 \mathrm{~L}$ polycarbonate carbouys (Nalgene) at $15^{\circ} \mathrm{C}$ with a photon flux density of ca. $70 \mu \mathrm{mol} \mathrm{PAR} \mathrm{m}^{-2} \mathrm{~s}^{-1}$ supplied by cool-white fluorescent lighting (Phillips, Netherlands) with a photoperiod of 12:12 h (light:dark). A Turner Trilogy fluorometer (Turner, USA) was used to monitor in vivo chlorophyll- $a$ fluorescence. The algal cultures were harvested when the culture reached peak in vivo fluorescence. Following algal growth in Erlenmeyer flasks, the cell biomass was removed by filtration through pre-combusted $\left(450^{\circ} \mathrm{C}\right.$ for $\left.8 \mathrm{~h}\right)$ glass fiber filters (GF/F; Whatman) and subsequently through deionisedwater rinsed and sterile polycarbonate filters $(0.2 \mu \mathrm{m}$; Millipore). Large volume algal cultures (10-20 L) were subjected to cross-flow filtration $(0.2 \mu \mathrm{m}$; Schleicher and Schuell) to remove algal and bacterial biomass. The seawater enriched with algal organic material was then stored frozen at $-20^{\circ} \mathrm{C}$ until use.

The organic matter isolated from these samples (whose organic carbon concentration is defined here as $\mathrm{OC}<0.2 \mu \mathrm{m})$ comprises microgels and colloidal nanogels along with truly dissolved organic carbon (Verdugo et al., 2004). It is suggested that aggregation of marine colloidal matter $<0.2 \mu \mathrm{m}$ is an important mechanism for the formation of aggregates in the supermicron size range (Wells and Goldberg, 1993). Facchini et al. (2008) found that most of the organic fraction in the primary aerosol submicron size distribution was water insoluble (WIOC) and that the composition of this fraction presented a similar signature to that of organic matter in the size range $0.1-10 \mu \mathrm{m}$, extracted from seawater. The origin of WIOC in the primary aerosol has been attributed to the colloidal organic matter secreted by phytoplanckton (Facchini et al., 2008). The samples used in the present study, although in a lower size range than the organic matter extracted for analysis by Facchini et al. (2008), contain an important part of the colloidal and microgel fraction of marine organic matter (Verdugo et al., 2004). Thus, the organic material in the samples employed in this study can contribute to the insoluble organic fraction observed in the submicron primary aerosol 
Table 2. Algal species employed for the production of exudate and $\mathrm{OC}_{<0.2 \mu \mathrm{m}}$ of seawater proxies prepared with a single algal exudate.

\begin{tabular}{llccc}
\hline Algal specie & Algal group & \multicolumn{3}{c}{$\mathrm{OC}_{<0.2 \mu \mathrm{m}}(\mu \mathrm{M})$} \\
\hline Thalassiosira rotula CCAP 1085/13 & Diatom & 175 & 300 & 512 \\
Chaetoceros sp. CCAP 1010/12 & Diatom & 175 & 300 & 512 \\
Emiliania huxleyi AC475 & PNAN, Coccolithophore & 175 & 512 & 2171 \\
Phaeocystis cf. globosa LY1 & PNAN, Prymnesiophyte & 175 & 512 & 910 \\
\hline
\end{tabular}

Table 3. Contribution of single algal exudates to the total organic carbon content of seawater proxies enriched with exudates mixtures (total $\left.\mathrm{OC}_{<0.2 \mu \mathrm{m}}=512 \mu \mathrm{M}\right)$.

\begin{tabular}{lrrrr}
\hline & \multicolumn{4}{c}{$\mathrm{OC}_{<0.2 \mu \mathrm{m}}(\mu \mathrm{M})$} \\
Mixture sample & T. rotula & Chaetoceros & E. huxleyi & \multirow{2}{*}{ Phaeocystis } \\
\hline TRotulamix & $256(50 \%)$ & $85.33(16.67 \%)$ & $85.33(16.67 \%)$ & $85.33(16.67 \%)$ \\
Chaetmix & $85.33(16.67 \%)$ & $256(50 \%)$ & $85.33(16.67 \%)$ & $85.33(16.67 \%)$ \\
EHuxmix & $85.33(16.67 \%)$ & $85.33(16.67 \%)$ & $256(50 \%)$ & $85.33(16.67 \%)$ \\
Phaeomix & $85.33(16.67 \%)$ & $85.33(16.67 \%)$ & $85.33(16.67 \%)$ & $256(50 \%)$ \\
\hline
\end{tabular}

Table 4. Summary of experimental conditions in the multiple plunging water jet system employed in this study. $Q_{w}=$ total water flow, $v_{1}=$ mean jet velocity at the water surface, $d_{0}=$ nozzle diameter, $h=$ vertical distance from the nozzle to the water surface, $z=$ penetration depth.

\begin{tabular}{lr}
\hline Number of water jets & 8 \\
$Q_{w}(\mathrm{lpm})$ & 4 \\
$v_{1}(\mathrm{~m} / \mathrm{s})$ & 1.11 \\
$d_{0}(\mathrm{~cm})$ & 0.4 \\
$h(\mathrm{~cm})$ & 4 \\
$z(\mathrm{~cm})$ & 7 \\
sweep air flow (lpm) & $3-3.5$ \\
\hline
\end{tabular}

composition (Facchini et al., 2008). It should be noted that although the term DOC (dissolved organic carbon) is generally applied to organic carbon with size $<0.5-0.7 \mu \mathrm{m}$ obtained after filtration, this term is defined as a function of size, not solubility, and thus, it is inappropriate for defining the organic carbon pool in this size range (Verdugo et al., 2004).

Two different methods were applied to prepare seawater proxies using the produced phytoplankton exudate. In the bulk mixing method, seawater solutions containing a single algal exudate type were prepared at organic carbon concentrations of the order of that in the seawater collected during the RHaMBLe cruise, in order to simulate the conditions expected near regions with high biological activity. To do this, artificial seawater devoid of exudate and aliquots of the stock solution of natural seawater enriched with organics were mixed to obtain the selected $\mathrm{OC}_{<0.2 \mu \mathrm{m}}$ concentration. Table 2 lists the algal exudates and the concentration of the seawater proxies prepared with each exudate type.

Additionally, seawater proxies containing a mixture of different exudates were prepared applying the bulk mixing method. Seawater samples at $512 \mu \mathrm{M} \mathrm{OC}<0.2 \mu \mathrm{m}$ concentration were made with one of the algal exudates comprising $50 \%$ of the total organic concentration, while the rest of the organic content was equally divided between the other three algal exudates on study (i.e. $16.67 \%$ of total $\mathrm{OC}_{<0.2 \mu \mathrm{m}}$ for each algal exudate). Table 3 summarises the distribution of the organic content with respect to the different algal exudates used for the preparation of each seawater proxy class.

With the monolayer method, the effect of organic microlayers on the particle production was investigated. Solid phase extraction (C-18 Sep-Pak SPE cartridges) was applied to extract the hydrophobic matter contained in $2 \mathrm{ml}$ of the aqueous exudates, by using $10 \mathrm{~mL}$ of a $2: 1$ volumetric mixture of chloroform and ethanol as extraction solvent. The solvent extracted samples were dried out and redissolved in chloroform and spread dropwise on the surface of artificial seawater contained into the bubble tank.

\subsection{Aerosol generation}

Bubble-bursting aerosols were produced by the impingement of water jets generated by means of a water recirculation system in the centre of a PTFE tank (Fig. 6). Air entrained in the water bulk as a result of the impingement of the liquid jets on the water surface, disperses in a plume of bubbles that burst on reaching the water surface. In order to generate a statistically significant number of particles for the aerosol 

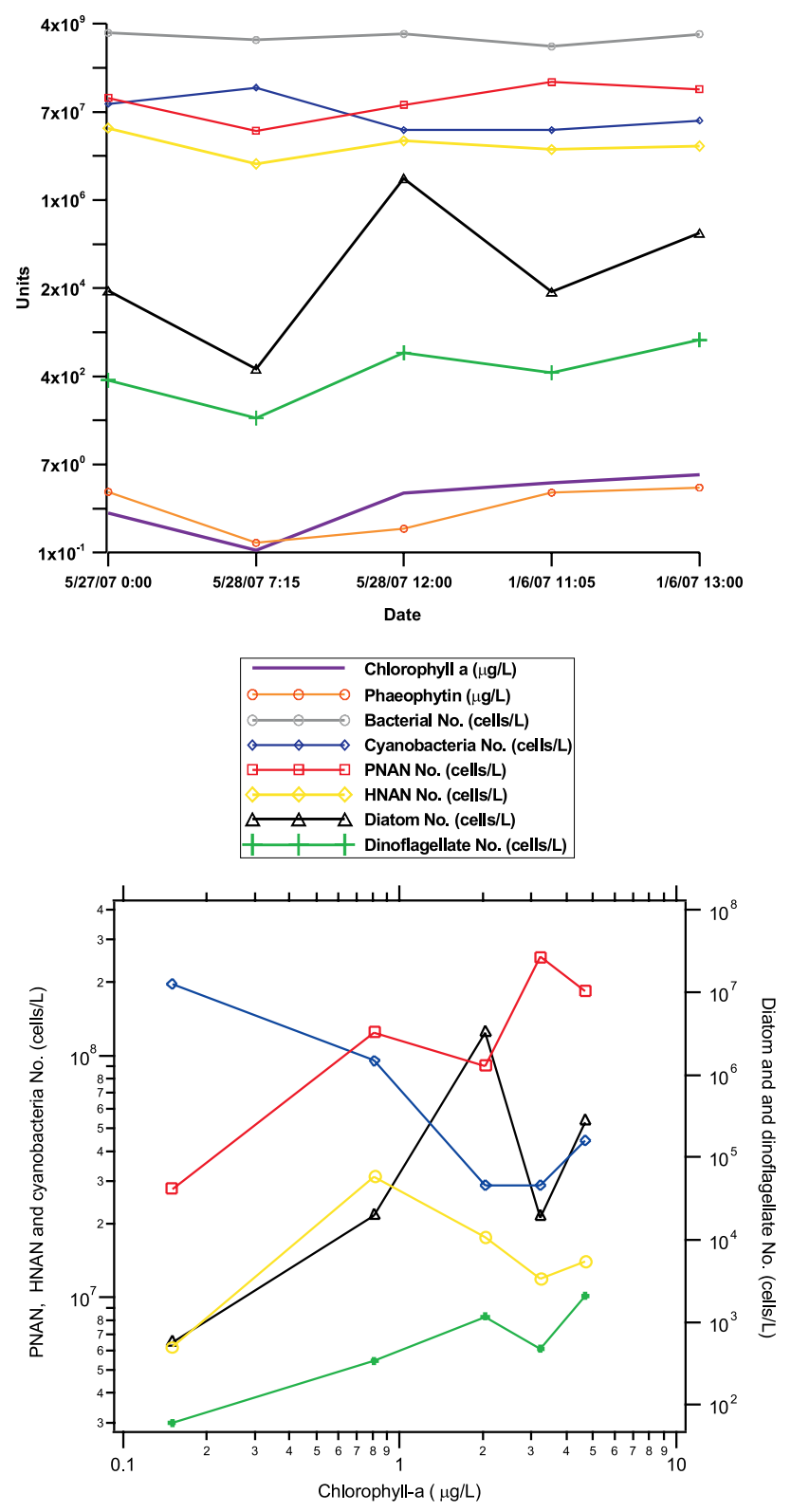

Fig. 2. Cells counts, chlorophyll- $a$ and phaeophytin analysis of samples collected during the RHaMBLe cruise (left) and relationship between phytoplankton and cyanobacteria cell counts with chlorophyll- $a$ concentration (right). The phytoplankton population was dominated by the nanoplankton group (HNAN: $10 \%$, PNAN, $89 \%)$, followed by diatoms $(0.5 \%)$ and dinoflagellates $(0.0005 \%)$.

experiments, the water flow was divided in eight water jets by using a flow distributor. A chemically resistant PTFE composite tube (Masterflex I/P 70) was employed for water recirculation in order to avoid contamination of the water samples and adhesion of surfactants on the tubing wall. The experimental conditions for the conducted measurements are summarised in Table 4.
For the aerosol experiments the PTFE tank was filled with $6 \mathrm{~L}$ of the prepared seawater proxy (Tables $2-3$ ), sealed and swept with a continuous air flow of 3-3.5 lpm. The humidity of the sample flow directed from the tank to the aerosol characterization instruments was reduced to $32-42 \%$ RH by mixing the sample with a $5 \%$ volumetric dry air flow, monitored by a mass flow controller, and by using a Nafion gas dryer. The relative humidity of the sample was monitored with a Rotronics HygroClip SC05 sensor positioned downstream of the gas dryer.

Thorough cleaning procedures were applied in order to minimize the presence of contaminants in the system. To do this, an isopropanol and deionised water solution was recirculated in the PTFE tank for an hour, followed by two sequential tank washes with 5 litres of deionised water. Next the tank walls were cleaned with chloroform, rinsed and washed with deionised water. In order to rinse the pump tubing, deionised water was recirculated through the tank tubing. Finally, the tank was washed twice with $5 \mathrm{~L}$ of deionised water.

Reduced inertial forces occurring in small-scale plunging water jet systems, as the one used in the present study, lead to the formation of shallow bubble plumes and, in consequence, to bubble paths and lifetimes shorter than those expected in real conditions (Fuentes et al., 2010). Theoretical analysis of surfactant adsorption by rising bubbles in a solution of marine algal exudate indicates that equilibrium adsorption is reached on a timescale considerably shorter than the bubble residence time in scaled system such as the present one (Fuentes et al., 2010). Instantaneous adsorption of surfactants on rising bubbles has also been found in theoretical and experimental studies with cationic surfactants (Morgan et al., 1992). As the steady state for surfactant adsorption is reached rapidly, bubble enrichment is not transport limited, thus, it will be assumed that the bubbles, and hence, the particle organic enrichment produced in the bulk mixing method experiments does not require scaling to the real time-scale conditions. In the experiments with organic monolayers the lifetime of the bubbles on the water surface might be too reduced to allow adsorption equilibration. However, if organics are in the form of microlayers on the ocean surface, a similar level of disequilibrium may pertain in oceanic conditions.

\subsection{Aerosol characterisation}

The size distribution of the aerosol generated from seawater proxies was measured using a Differential Mobility Particle Sizer (DMPS). The DMPS consists of two Vienna design Differential Mobility Analysers (DMAs) (Williams, 1999; Williams et al., 2007): an ultrafine DMA for particles in the size range $3.4-34 \mathrm{~nm}$ and a standard DMA for particle sizes from $30-830 \mathrm{~nm}$. After transmission through the DMAs, particles are counted using condensation particle counters (CPC). The ultrafine DMA was attached to a TSI 3025A CPC counter and the standard DMA to a TSI 3010 CPC particle 

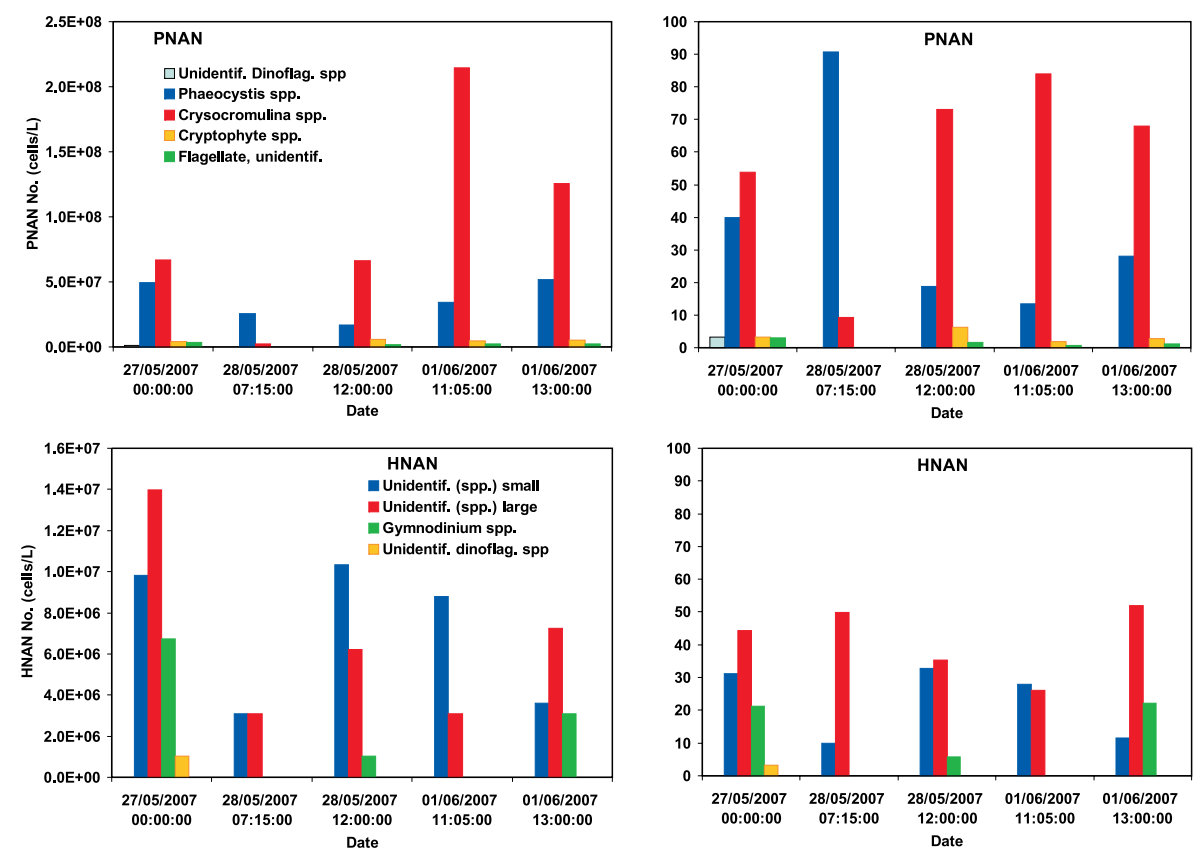

Fig. 3. Total and normalized cell counts for photosynthetic nanoplankton (PNAN) and heterotrophic nanoplankton (HNAN) populations in the oceanic seawater samples collected during the RHaMBLe cruise. Crysocromulina and Phaeocystis were identified as dominant species in the nanoplankton group.
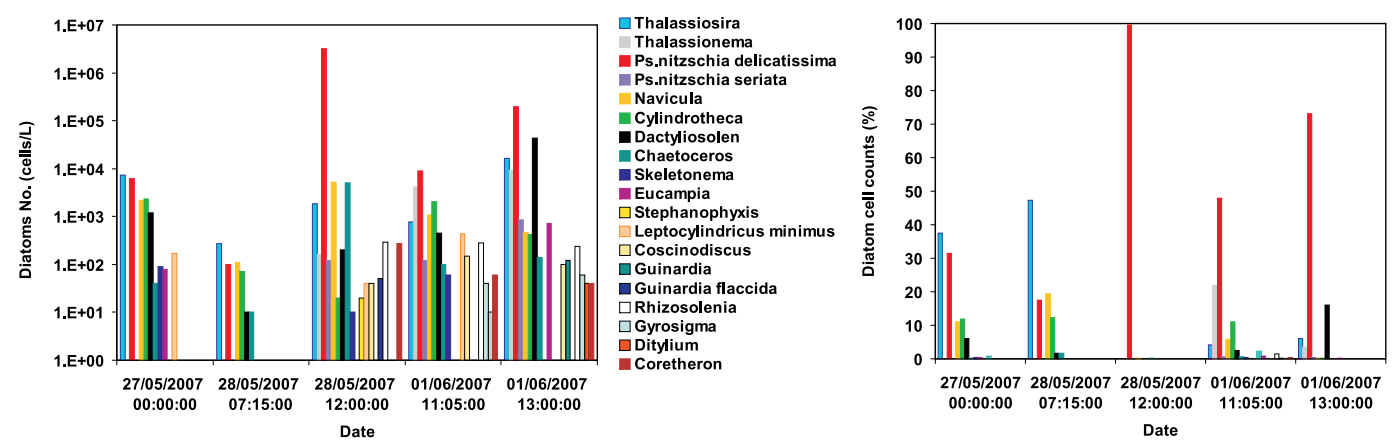

Fig. 4. Total and normalized cell counts for the diatom population in the oceanic seawater samples collected during the RHaMBLe cruise (color legend is in the same order as plot bars). The analysis identified Ps.nitzschia delicatissima and Thalassiosira as the dominant diatom species in the seawater samples.
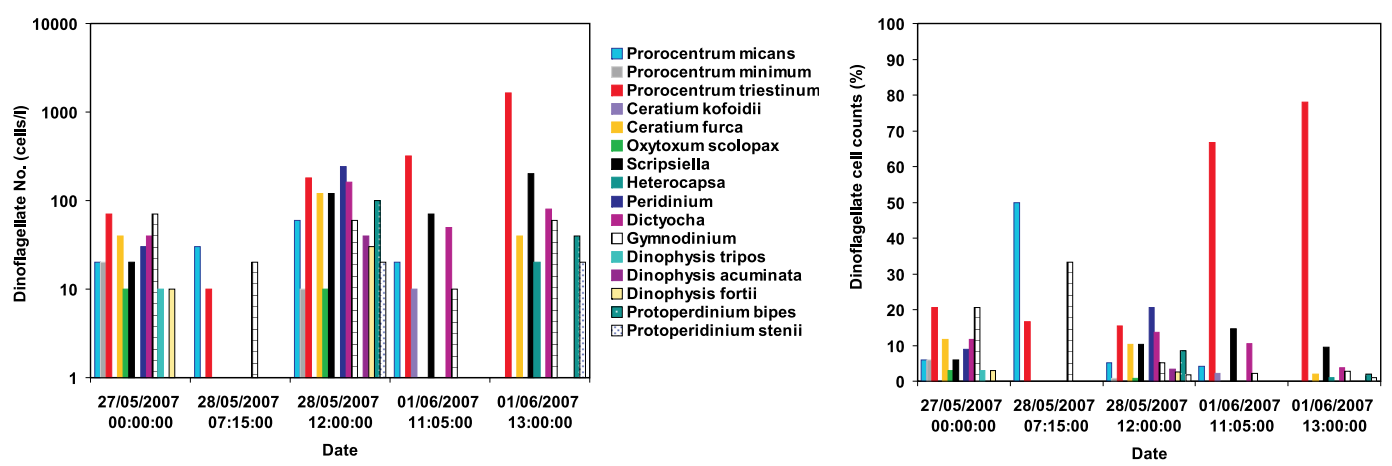

Fig. 5. Total and normalized cell counts for the dinoflagellate population in the oceanic seawater samples collected during the RHaMBLe cruise (color legend is in the same order as plot bars). Results indicated that Prorocentrum species were dominant in the dinoflagellate group. 


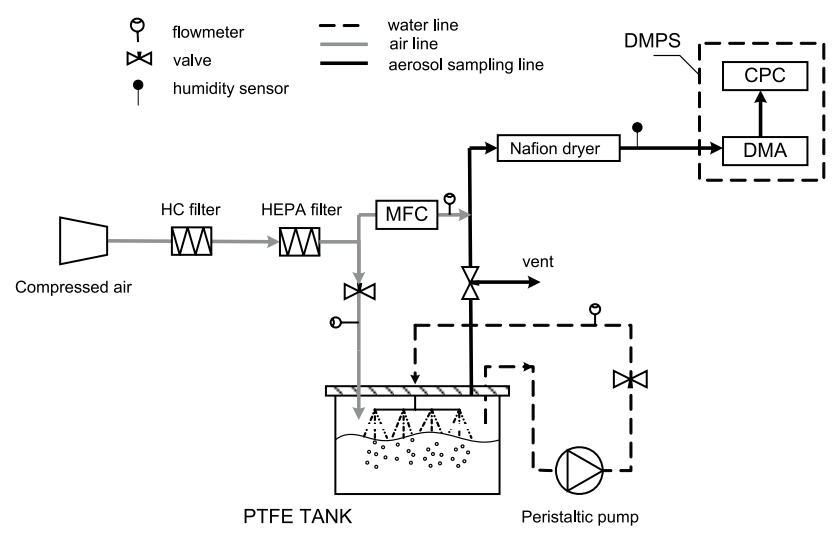

Fig. 6. Schematic of experimental set-up for the measurement of the size distribution of primary sea spray generated by water impingement.

counter. The DMAs were operated in parallel and utilised a custom built sealed, recirculating sheath air system, which was humidity controlled and filtered. Particle size distributions in the dry diameter size range from $3 \mathrm{~nm}$ to $450 \mathrm{~nm}$ were obtained as the average of 6 scans during a 60 minute measurement period. All the laboratory measurements were conducted at $\sim 20^{\circ} \mathrm{C}$. Due to the limited amount of organicenriched seawater available, the sample was not replaced during the duration of the aerosol experiments. Time series of particle size distribution measurements did not indicate any significant changes during the duration of the experiments.

Seawater samples were collected along the RHaMBLe cruise track for the on-board production of primary aerosol by using the plunging-waterjet aerosol generator, operated with two water jets. Two to three seawater samples were collected daily with time intervals of $3-4 \mathrm{~h}$ in the period from 30 May to 5 June. The experiments were conducted within an hour after collection. The size distribution of the produced particles was characterized by means of a Scanning Mobility Particle Sizer (SMPS) (TSI Inc Model 3936NL25), which consists of a Model 3080 classifier and a 3025A-S condensation particle counter. Measurements in the size range from $7.4 \mathrm{~nm}$ to $289 \mathrm{~nm}\left(D p_{0}\right)$ were obtained as the average of 12 scans during a $60 \mathrm{~min}$ measurement period. The on-board measurements were conducted at $\sim 23^{\circ} \mathrm{C}$.

Blank tests were performed prior to the experiments by measuring the particle counts in the sample air flow from the tank head space in the absence of bubbles. Bubbling experiments were initiated when the particle counts detected in the blank air were zero. The measurements were corrected for particle losses by considering the calculated transmission efficiency from the tank to the instruments as a function of the particle size. Most particle losses (up to 75\% loss) occurred in the size range below $20 \mathrm{~nm}$, as a result of diffusion.

\subsubsection{Particles morphology considerations}

For cubic particles, such as $\mathrm{NaCl}$, a standard shape factor of $\chi=1.08$ is generally applied in order to reconcile the mobility and volume equivalent diameters. This correction is necessary to estimate the particles hygroscopic growth and the volume equivalent diameter, usually employed as input parameter for calculations based on the Köhler theory. $\mathrm{NaCl}$ is an important component in both the artificial and natural seawater samples used in this study; however, transmission Electron Microscope images of particles generated from artificial and natural seawater by bubble bursting have shown that in the presence of organics and other inorganic salts the morphology of these particles may differ from the well-known cubic shape of $\mathrm{NaCl}$ particles (Wise et al., 2009).

Because of the high hygroscopicity of sea spray particles, some water is probably absorbed on the particles at the relative humidity for size selection in the DMA (32-42\% RH); however, it is not clear to what extent the water absorbed by the particles at this humidity can induce a change to spherical shape. Although the onset of particle morphology change for sea spray particles has been observed to occur at $45 \%$ $\mathrm{RH}$, particle rounding does not take place until $65 \% \mathrm{RH}$ is reached (Wise et al., 2009). In this study a shape factor of $\chi=1.04$ is applied, the mean value in the range from spherical $(\chi=1)$ to cubic shape $(\chi=1.08)$, implying an uncertainty of $4 \%$ in the determination of the selected particle size.

\section{Results of aerosol experiments}

\subsection{Bubble spectrum}

The study of the number and size of sea salt drops ejected by individual bubbles have demonstrated that the relative contribution of jet and film drops to the aerosol production depends critically on the characteristics of the parent bubble size distribution (Spiel, 1997; Wu, 2002). Laboratory reproduction of the oceanic bubble spectrum would therefore be relevant for the generation of a representative marine aerosol.

The bubble spectrum generated by the plunging water jet system operated with a single water jet in artificial seawater was evaluated in Fuentes et al. (2010). This bubble spectrum is presented in Fig. 7 along with laboratory bubble spectra produced in artificial seawater (Sellegri et al., 2006) and natural seawater (Hultin et al., 2009) by water impingement in other laboratory studies. In this plot it is particularly noticeable that very similar shapes are found between the bubble spectrum produced by the system employed in this study with artificial seawater (Fuentes et al., 2010) and the one obtained with natural seawater by Hultin et al. (2009). However, from this comparison it is not possible to conclude that similar bubble spectra are produced in natural seawater and seawater devoid of marine surfactants, as it is unknown whether these measurements were conducted 


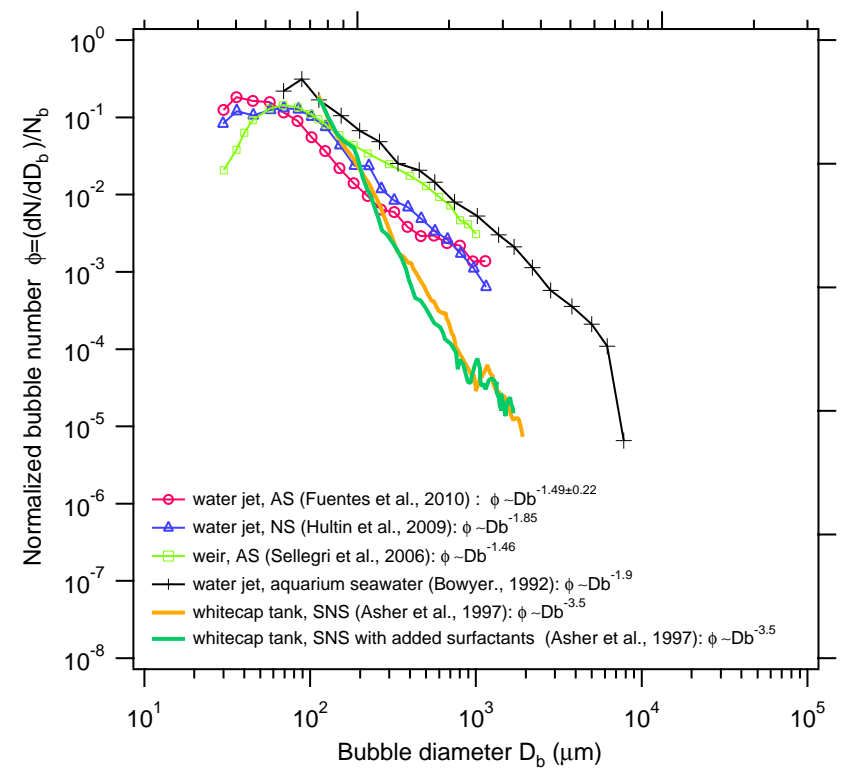

Fig. 7. Comparison of normalized bubble populations generated by seawater impingement in different laboratory studies. The water impingement-generated bubble distributions present a common dominant mode in the $40 \mu \mathrm{m}$ to $110 \mu \mathrm{m}$ bubble size region followed by a decrease in the bubble number with power-law exponents between 1.46-3.5 (AS=artificial seawater, NS=natural seawater, $\mathrm{SNS}=$ sterilised natural seawater).

at similar locations with respect to the impingement zone. Notwithstanding the difficulty of comparing between the different cases, because of the dependency of the measurements on the relative position of the measuring system with respect to the impingement area, it is observed that all the distributions exhibit a dominant peak in the $40 \mu \mathrm{m}$ to $110 \mu \mathrm{m}$ region, followed by a decrease in the bubble number with increasing size. The power-law exponent of the different curves varies between 1.46 and 3.5, which is within the range of values found for oceanic bubble spectra (Lewis and Schwartz, 2004). The similarities between the bubble spectra produced in water impingement simulation experiments and oceanic bubble spectra profiles is discussed in Fuentes et al. (2010). In the study of Asher et al. (1997) the addition of surfactants to sterilised natural seawater did not produce significant changes in the bubble spectra generated by water impingement (Fig. 7). Although both surfactants and electrolytes are known to affect the bubble size distribution formed in freshwater solutions (Xu et al., 2009), the experiments of Asher et al. (1997) indicate that the effect of surfactants on the bubble spectrum is negligible in the presence of electrolytes at concentrations occurring in seawater.

The multiple water jet system employed in the present study was hydrodynamically scaled with respect to the single water jet system used to measure the bubble spectrum shown in Fig. 7 (see Fuentes et al. (2010) for a detailed description). This scaling procedure ensures equivalence between the void fraction and the normalized bubble spectra of the single and the multiple water jet systems. In order to derive the bubble spectrum generated by the multiple jet system, scaling of the bubble spectrum produced by the single water jet generator to the multi-jet configuration should be applied. To do this, the air entrainment associated with the individual jets in the multijet system and the number of water jets has to be considered. This calculation is applied to derive the surface area covered by bubbles as described in Sect. 5 .

\subsection{Aerosol size distribution measurements}

Size distributions of the aerosol generated from seawater proxies enriched with $T$. rotula and Chaetoceros exudates, prepared using the bulk mixing method, are shown in Fig. 8. For comparison, these curves have been represented together with the measurements for artificial seawater devoid of exudate and natural seawater plus the nutrients medium used for growing the algal culture. Although the majority of the added nutrients are supposed to be consumed by the algae during the growth period, the seawater+algal medium measurement has been included in order to compare with the measurements conducted with the samples resulting after algal growth.

For a detailed analysis of these measurements each size distribution was decomposed into lognormal modes by applying least square fitting to the experimental data. In all cases the size distributions were found to be well-represented by four lognormal modes, with modal sizes of $\sim 15 \mathrm{~nm}$, $\sim 45 \mathrm{~nm}, \sim 125 \mathrm{~nm}$ and $\sim 340 \mathrm{~nm}$, respectively (see supplementary material, Figs. S1 and S2). The definition of the size distribution as a function of lognormal modes is used here as a convenient mathematical construct to represent and interpret the physical distribution, without attributing any physical significance to these lognormal modes.

The measurements in Fig. 8 show that a shift of the size distributions to smaller sizes and an increase in the number of particles with $D_{p 0}<100 \mathrm{~nm}$ occur as the water organic content is increased. The similarity between the natural seawater+nutrients medium and the artificial seawater measurements shows that the added nutrients do not produce any effect on the size distribution. Thus, it is evident that the changes observed in the size distribution are induced by the organic matter released during algal growth. Figure 9a-g illustrates the effect of the seawater organic concentration on the properties of the lognormal modes comprising the size distributions presented in Fig. 8. The trends in the total particle number and mean diameter represented in these plots indicate that the effect observed on the size distributions manifests itself as an increase in the particle number of the second lognormal mode (modal size $\sim 45 \mathrm{~nm}$ ) and the reduction in the modal size of all the lognormal modes with increasing organic concentration. The observed reduction of the modal sizes ranges from $\sim 16 \%$ for modes 1 and 2 to $\sim 4-6 \%$ for modes 3 and 4 . The particle number of the third lognormal 

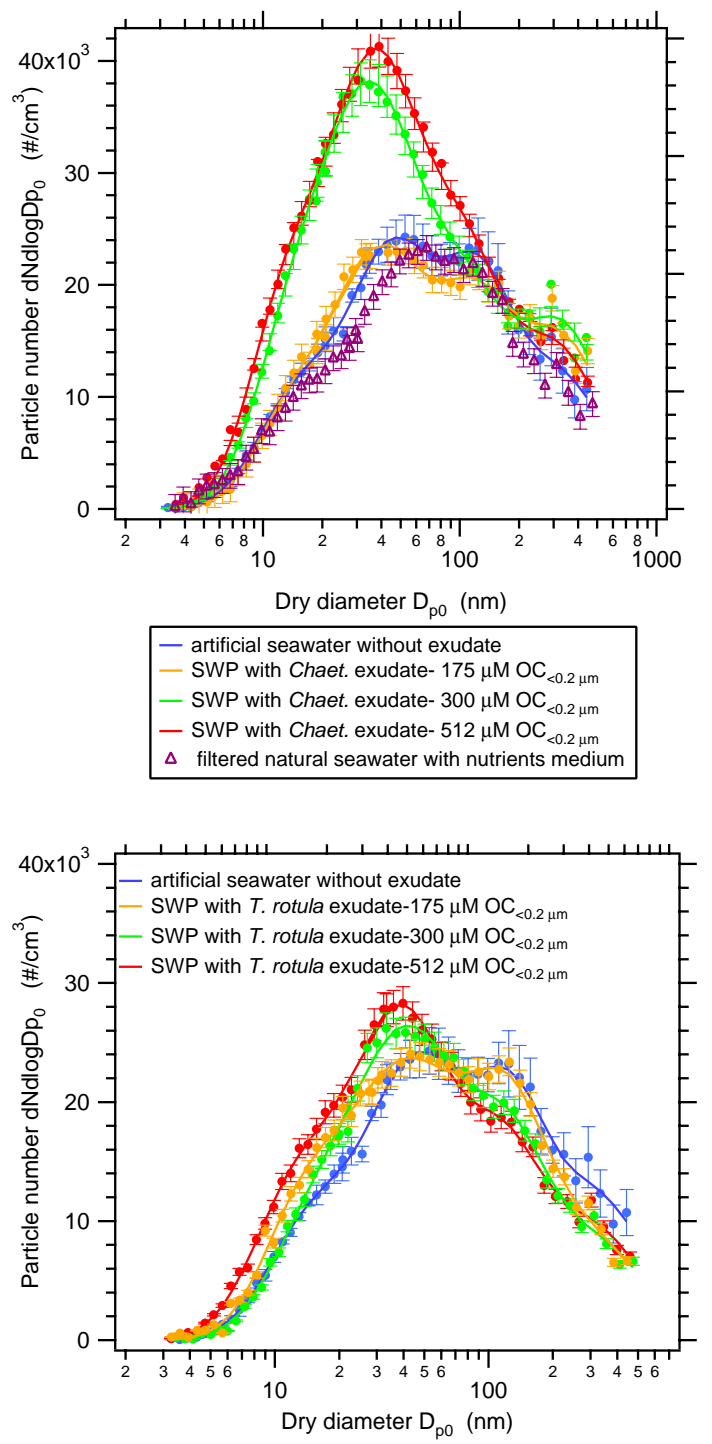

Fig. 8. Particle size distributions obtained for artificial seawater without exudate and seawater proxies (SWP) enriched with T. rotula and Chaetoceros exudates at different $\mathrm{OC}_{<0.2 \mu \mathrm{m}}$ concentrations. Error bars indicate the variability of the measurements obtained from 6 scans during $1 \mathrm{~h}$ period as $\pm 1 \sigma$ standard deviation.

mode, centered at $\sim 125 \mathrm{~nm}$ was observed to decrease, which also contributes to the shift of the size distribution to smaller sizes. It should be noted that the change in the lognormal parameters is a manifestation of the effect of the organic matter on the particle production, which can be used as a way to represent the phenomenon, but that does not provide any insight into the physical process that modifies the size distribution properties.

In order to compare the effect of the algal exudate type on the particle size distribution, Fig. 10 (top) shows the experiments conducted with seawater at $512 \mu \mathrm{M} \mathrm{OC}_{<0.2 \mu \mathrm{m}}$ con-
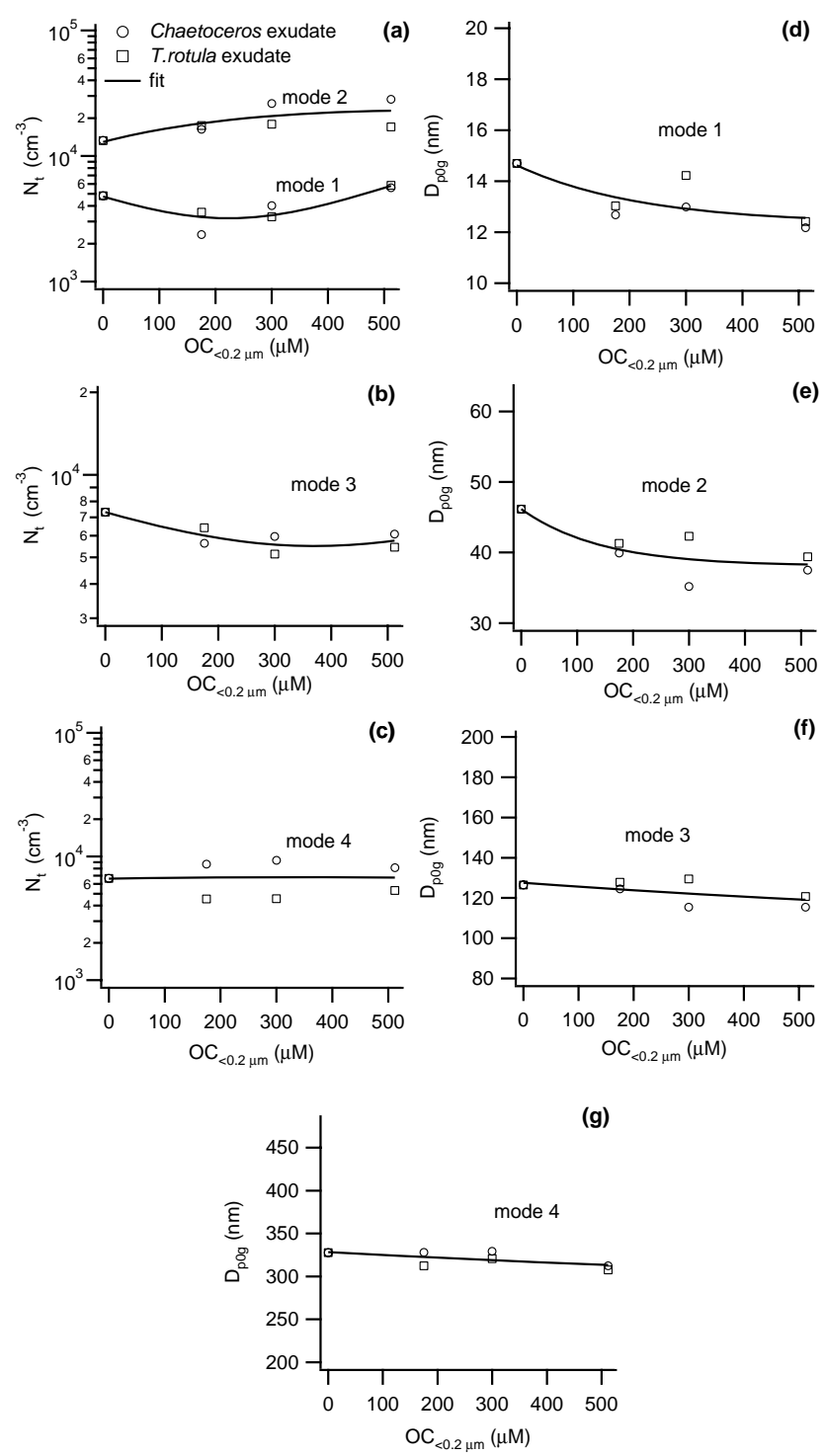

Fig. 9. Effect of organic exudate concentration on the total particle number $N_{t}(\mathbf{a}, \mathbf{b}, \mathbf{c})$ and geometric mean $D_{p 0 g}(\mathbf{d}, \mathbf{e}, \mathbf{f}, \mathbf{g})$ of the four lognormal modes comprising the particle size distributions generated from seawater enriched with Chaetoceros and T. rotula exudates (lognormal modal sizes $\left(D p_{0}\right)$ : mode $1, \sim 12-15 \mathrm{~nm}$; mode 2 , $\sim 37-46 \mathrm{~nm}$; mode 3, $\sim 115-127 \mathrm{~nm}$; mode 4, $\sim 315-328 \mathrm{~nm}$ ).

centration for all the algal exudates on study. Whereas the diatomaceous exudate (T. rotula and Chaet.) size distributions are affected by the presence of organic matter with respect to the case without marine organics, no significant effects were observed for the experiments with nanoplankton exudates $(E$. huxleyi and Phaeocystis) in the range of concentrations studied (see Fig. S3 in supplementary material). Regarding the experiments conducted with the monolayer method (Fig. 10, bottom), no effects were observed on the size distribution for these measurements. This could indicate that the existence of a single monolayer is not sufficient to exert any significant 

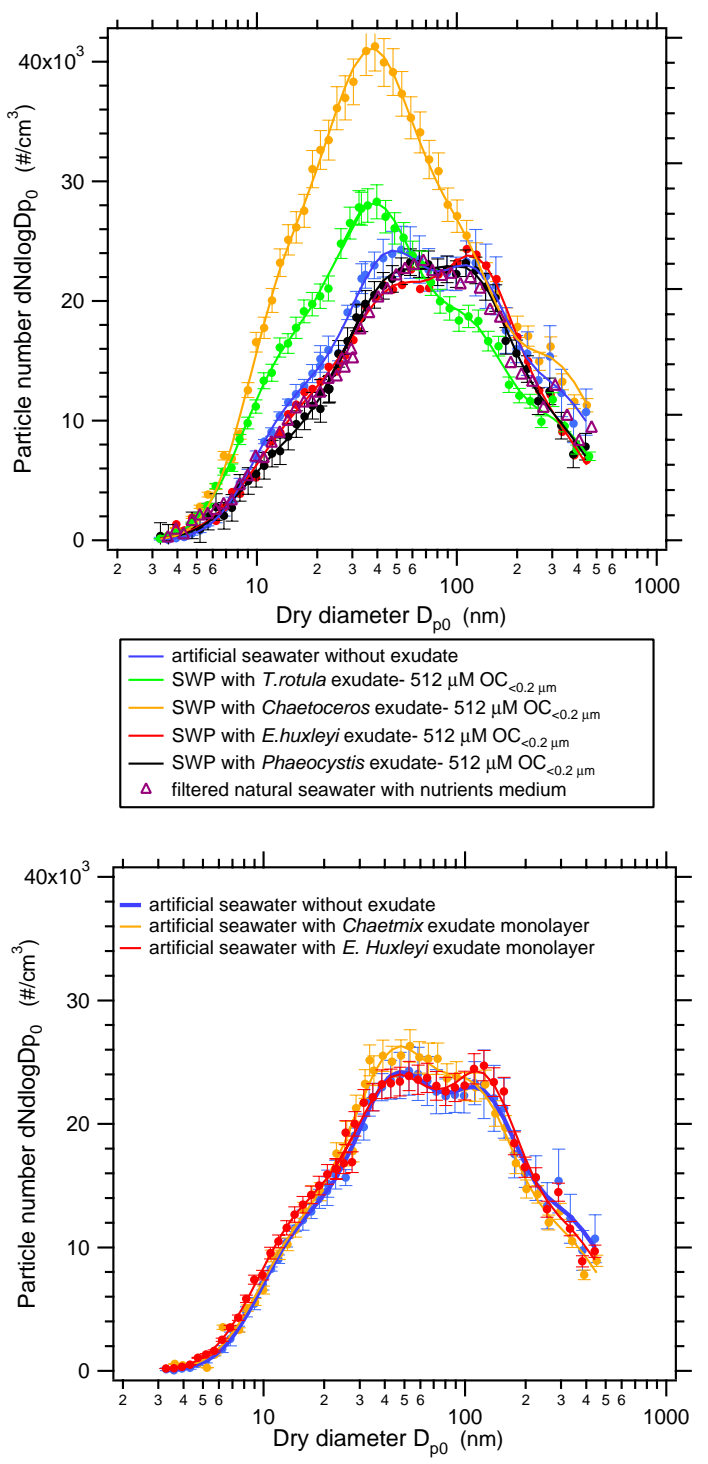

Fig. 10. Comparison of the particle size distribution for artificial seawater without added surfactants and seawater proxies (SWP) enriched with single algal exudates at $512 \mu \mathrm{M} \mathrm{OC}<0.2 \mu \mathrm{m}$ concentration (top) and size distributions obtained with the monolayer method (bottom). The size distribution obtained from filtered natural seawater with added nutrients (=filtered natural seawater with $\mathrm{f} / 2$ medium) is included for comparison. Error bars indicate the variability of the measurements obtained from 6 scans during $1 \mathrm{~h}$ period as $\pm 1 \sigma$ standard deviation.

effect on particle production. It should be noted, however, that the organic layer was not replenished during the duration of the experiments, thus, removal of the monolayer by bubble bursting might have occurred on a timescale shorter than the time required to obtain a measurement. Also, the time for adsorption of organic material onto the bubble prior to bursting may be too reduced for adsorption equilibrium to be reached, explaining why no effects were observed.
The results obtained with seawater enriched with mixtures of algal exudates are shown in Fig. 11. Although the nanoplankton exudates alone did not produce any effect on the size distributions, when they were combined with the diatomaceous exudate, a shift of the aerosol size distributions toward smaller sizes was observed. In the same way that the previous analysis of the diatomaceous exudate measurements, decomposition of the distribution into lognormal modes indicates that the effect is due to the reduction in the modal size and the increase in the particle number of the second lognormal mode at $\sim 45 \mathrm{~nm}$, together with the reduction of the third lognormal mode centered at $\sim 125 \mathrm{~nm}$ (Fig. 11) (the indicated modal sizes refer to the case without added organics). The largest effect observed was for the Chaetmix experiment, which is the mixture that contains the largest proportion of Chaetoceros exudate. This exudate type also caused the greatest effect in the experiments with single exudates. Measurements with the algal mixtures confirm that the organics in the diatomaceous exudates influence the particle production, while the nanoplankton exudate does not induce any change.

It is interesting to compare the measurements shown herein with studies by Sellegri et al. (2006) and Tyree et al. (2007), who examined the effect of SDS and oleic acid in seawater, as surfactant surrogates, on the production of marine particles by bubble-bursting. In an analogous manner to the present study, a shift of the marine submicron size distribution to smaller sizes was observed in both studies with the addition of amounts $\geq 3 \mathrm{mgL}^{-1}$ of SDS and $\geq 0.1 \mathrm{mgL}^{-1}$ of oleic acid to artificial seawater. In a similar way to the presented measurements, an increase in the particle production, together with the size distribution shift, was reported by Tyree et al. (2007) in their experiments with oleic acid.

The analogous trends observed with diatomaceous exudate, SDS and oleic acid suggest that the effect on particle production is related to the surface-active properties of all these compounds. Surfactants are considered to affect bubble hydrodynamics through effects on bubble motion and rise speed (Batchelor, 1967). Bubble bursting has been found to be significantly altered by the addition of surfactant, which particularly affects the height and width of the bursting jet formed and the number of drops released (Boulton-Stone, 1995; Dey et al., 1997). Photographic experiments conducted by Dey et al. (1997) have shown that the addition of surfactants produces slower bubble bursting jets, with wider base and narrower tips. This leads to the formation of tiny droplets that appear to be released from the front of the bursting jet during the early stages of jet formation. Considering these observations, it is reasonable to assume that there exists a connection between the impact of surfactants on the bubble bursting process and the modification of the particle production observed in the present and other studies with surfactant surrogates (Sellegri et al., 2006; Tyree et al., 2007). Notwithstanding the similar effect produced by the different surfactants, it is not possible to conclude that SDS and oleic 

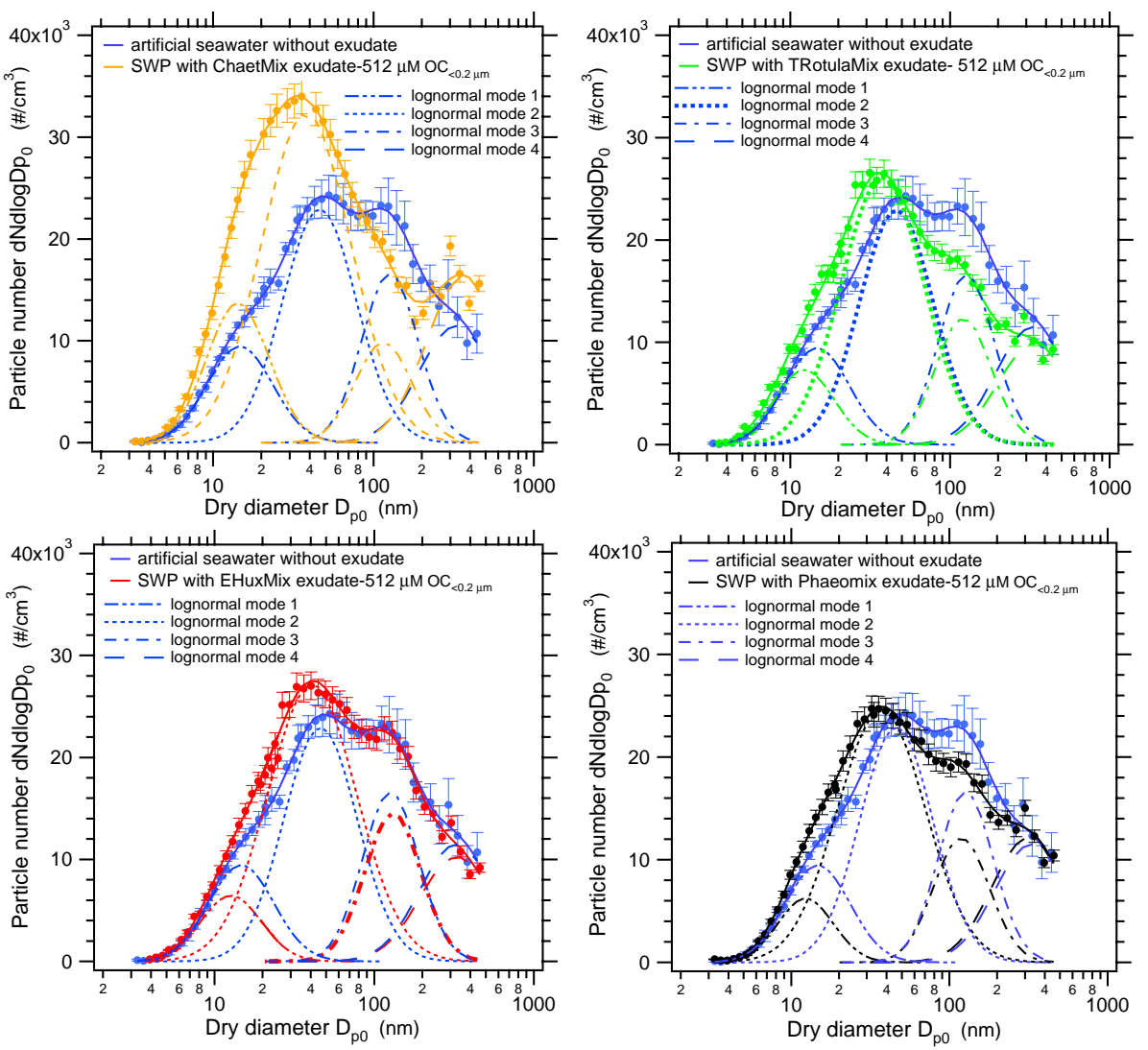

Fig. 11. Particle size distributions obtained for artificial seawater without exudate and seawater proxies enriched with mixtures of different algal exudates at $512 \mu \mathrm{M} \mathrm{OC}<0.2 \mu \mathrm{m}$ concentration. Error bars indicate the variability of the measurements obtained from 6 scans during $1 \mathrm{~h}$ period as $\pm 1 \sigma$ standard deviation.

acid are valid as proxies of marine organic matter. A broader characterization of the physical and chemical properties of particles enriched with these substances, such as hygroscopic and CCN properties, should be performed in order to assess the adequacy of these compounds for representing marine organics.

Tyree et al. (2007) explored the effect of marine organics on the primary particle production by generating aerosol from seawater proxies prepared by mixing filtered natural seawater and artificial seawater at different ratios. In contrast to the present study, these authors did not find a correlation between the particle production and the concentration of organics in seawater proxies. This discrepancy is most likely due to differences in the method of particle production and the properties of the seawater samples employed for conducting the measurements. Primary aerosol organic enrichment has been shown to depend on the system for particle production (Fuentes et al., 2010). Thus, the use of a different aerosol generation mechanism in the present study (bubblebursting induced by water impingement) and Tyree et al. (2007) (bubble-bursting induced by injecting air through a porous frit) might partly explain the differences between the results.
In addition, the effect of organics on the size distribution has been shown to be dependent on the seawater organic concentration and the type of algal exudate. Significant effects on the particle production have only been observed for minimum concentrations between $175 \mu \mathrm{M}$ and $300 \mu \mathrm{M} \mathrm{OC}_{<0.2 \mu \mathrm{m}}$ of diatomaceous exudate in this work. The natural seawater samples employed by Tyree et al. (2007), although enriched in organics (maximum concentrations of $250 \mu \mathrm{M}$ and $190 \mu \mathrm{M}$ $\mathrm{OC}_{<0.7 \mu \mathrm{m}}$ ), were probably not enriched enough in the organic surfactants present in the diatomaceous exudate that are able to produce an effect on the particle production. This is illustrated in the experiments conducted with nanoplankton exudate, where for unrealistically high organic carbon concentrations (910-2100 $\left.\mu \mathrm{M} \mathrm{OC}_{<0.2 \mu \mathrm{m}}\right)$ there was not any effect on the particle production (see Fig. S3 in supplementary material).

The fact that effects on the particle size distributions were only observed with the diatomaceous exudates suggests that different type or amounts of surfactants are produced by the diatoms species as compared to the nanoplankton strains tested. The transport of surfactants from seawater to the airwater interface is closely related to the chemical properties of the material in the seawater medium (Tseng et al., 1992). 

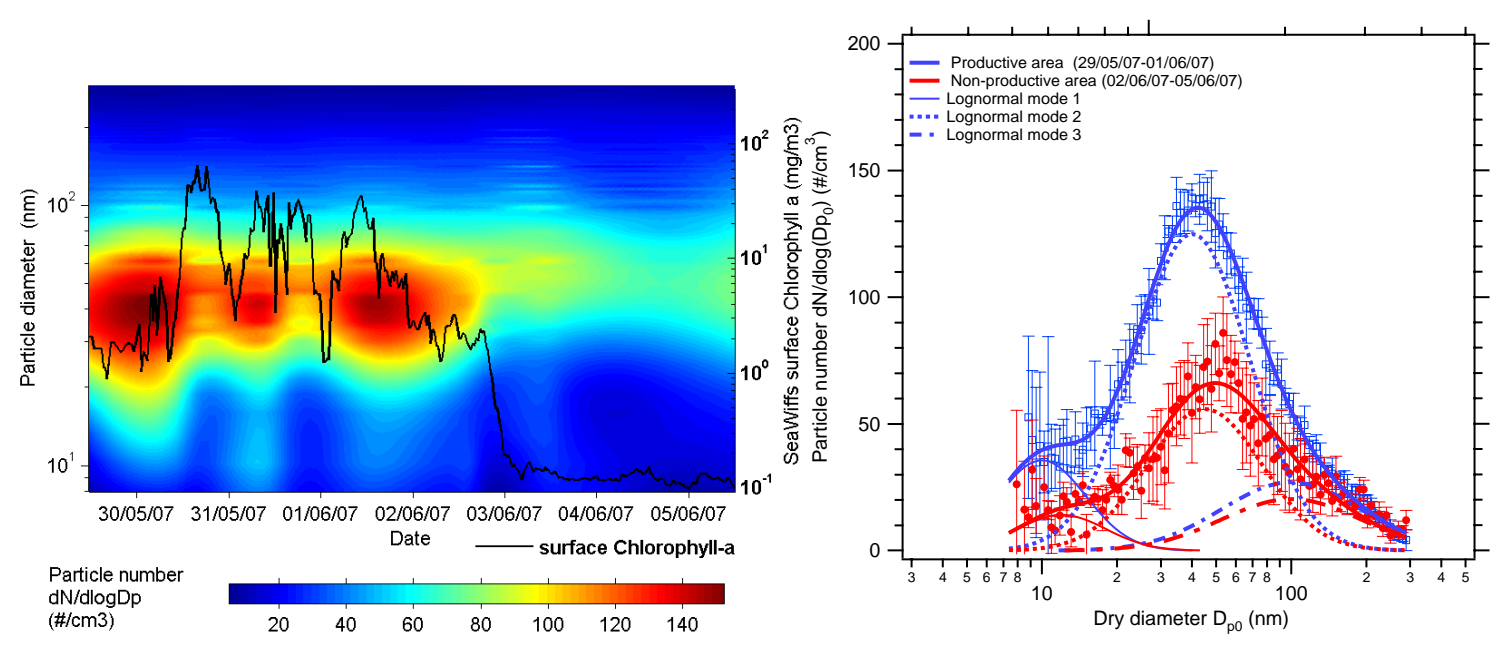

Fig. 12. Evolution of the size distribution of primary aerosol generated by bubbling unfiltered seawater during the RHaMBLe cruise ( $29^{\text {th }}$ May- 5 June) and seawater chlorophyll- $a$ concentration (derived from SeaWiffs ocean color data) along the cruise track (left). Mean particle size distributions measured inside and outside the productive area during the RHaMBLe cruise (right) and decomposition into lognormal modes. Measurements were conducted at $\sim 23^{\circ} \mathrm{C}$. Error bars indicate the variability of the measurements obtained from 6 scans during $1 \mathrm{~h}$ period as $\pm 1 \sigma$ standard deviation.

Tseng et al. (1992) found that oleic acid, stearic acid, triolein, and cholesterol in seawater were transported to particles generated by bubble bursting in decreasing order in direct relationship to their susceptibility to be absorbed by rising bubbles. The dependence of the produced effect on the type of organic exudate is likely to be related to the chemical properties of the surfactants secreted by diverse algal strains. It has been shown that the photosynthetic extracellular release depends on the taxonomic composition of the phytoplankton populations (Wolter, 1982). Comparative analysis of the exudates released by a number of diatom species has shown differences in the excretion rate between strains within the same taxonomic group (Myklestad, 2000). These examples show clearly that the composition of the algal population has to be taken into consideration, however, further research is needed to establish correlations between the exudates chemical composition and the observed phenomena in order to fully elucidate this stated hypothesis.

The results presented in the current study indicate that interpretation and comparison of the effect of organic matter on the production of marine aerosol should be made in light of the dependencies found regarding the seawater organic enrichment and type of organic exudate. The presented results show that a minimum concentration between $175 \mu \mathrm{M}$ and $300 \mu \mathrm{M} \mathrm{OC}<0.2 \mu \mathrm{m}$ of diatomaceous exudate was needed to observe significant effects on the particle production. Since the average concentration of organic matter in oceanic surface waters is reported to be $50-80 \mu \mathrm{M}$ $\mathrm{OC}_{<0.5-0.7 \mu m}$ (Owaga and Tanque, 2003), the observed effects on particle production would only be significant in bloom areas, where $\mu \mathrm{M} \mathrm{OC}<0.2 \mu \mathrm{m}$ concentrations can reach values higher than $300 \mu \mathrm{M}$ (Ittekot (1982) and data in Ta- ble 1), with a regional abundance of diatoms. Diatoms are major contributors to the organic pool in seawater and are frequently found as a dominant group in plankton blooms (Lavender et al., 2008; Meskhidze and Nenes, 2006; Ittekot, 1982).

\subsection{RHaMBLe field size distributions}

The evolution of the size distribution of primary sea spray generated during the RHaMBLe cruise using unfiltered oceanic seawater is shown in Fig. 12, together with the chlorophyll- $a$ concentration along the cruise track (derived from the SeaWiffs satellite data, May 2007). The productive and non productive regions can be identified by observing the Chl- $a$ profile along the cruise track, which indicates 2 June as the delimiting date for the transition from the productive to the non-productive zone.

Although it is not observed a clear correlation between the chlorophyll- $a$ profile and the particle size distributions inside the bloom region, both the particle production and the chlorophyll- $a$ concentration drop on departing the productive area. In addition, the modal size of the distribution is shifted from circa $40 \mathrm{~nm}$ within the productive area to a larger value of $52 \mathrm{~nm}$, outside the productive area.

In order to illustrate the differences between the productive and non-productive zones, Fig. 12 (right) shows the mean size distributions measured inside and outside the bloom area. Three lognormal modes were found in these size distributions. The fourth lognormal mode at $\sim 340 \mathrm{~nm}$ detected in the size distributions produced from water proxies is not captured here due to the narrower size range covered by the SMPS instrument. The number of particles with 
$D_{p 0}<100 \mathrm{~nm}$ was larger in the productive area than in the non-productive region due the lower modal size and higher particle number that the lognormal mode centered at $\sim 45 \mathrm{~nm}$ presents in the bloom region. This behaviour parallels the trends observed in the presented experiments with seawater proxies with and without exudate. As the seawater employed for the on-board measurements was not subjected to filtration, the observed effect could be attributable to detritus, organic macrogels and colloidal and dissolved organic carbon (Verdugo et al., 2004).

In the ocean, phytoplankton populations are exposed to varying stress conditions different to those in laboratory cultures (e.g. light, pH, temperature, nutrients, virus and bacterial attack), which might affect the metabolic activity and organic matter released by the algal cells. The comparable trends between the laboratory measurements conducted with exudate from algal cultures and the on-board experiments with oceanic samples indicate that, notwithstanding the different conditions for algal growth, the exudate from algal cultures performs in a similar manner to the organic matter produced in real conditions.

Long-term observations of marine aerosol in North Atlantic waters by O'Dowd et al. (2004) and Yoon et al. (2007) have revealed seasonal variation in the characteristics of the atmospheric marine aerosol size distribution. This variation was typified by a higher particle number (Aitken mode), particle size and particle organic enrichment during high biological activity periods (spring and summer) compared to low productivity periods (winter). The increase in the particle number with the addition of organic matter observed in the laboratory and on-board experiments during the RHaMBLe cruise are in agreement with the increase in the particle production during high productivity periods observed by O'Dowd et al. (2004). However, it should be considered that the atmospheric aerosols are affected by factors such as temperature, wind speed and secondary aerosol production processes of biogenic, anthropogenic and terrestrial origin. Thus, direct extrapolation of primary aerosol experiments to atmospheric observations requires the factoring in of these additional functions.

In an attempt to explain the seasonal variability of the marine aerosol distribution it has been postulated that the increase in the modal sizes occurring from winter to summer is related to the impact of the higher biological activity occurring during warm periods on the primary aerosol production (O'Dowd et al., 2004; Yoon et al., 2007). In contrast to this hypothesis, the results presented in the present study show that, if there is a contrasting effect, it is to reduce the modal sizes with increasing amounts of phytoplankton-derived organic matter in seawater. This behaviour was observed when bubbling with both unfiltered seawater and seawater proxies with colloidal organic carbon $<0.2 \mu \mathrm{m}$. This suggests that the seasonal evolution of the modal sizes observed by O'Dowd et al. (2004) is not directly driven by the increase in the primary biogenic matter production during warm peri- ods, if the same processes are at play. It would then be necessary to invoke other reasons such as temperature, wind speed or aerosol secondary formation processes to explain the observed modal increase in the spring-summer periods. Sellegri et al. (2006) found that a shift of the modal diameters of the sea-spray distribution occurred with the increase of the temperature from $4{ }^{\circ} \mathrm{C}$ to $23^{\circ} \mathrm{C}$. This would imply that the temperature rise from winter to summer would produce an increase in the modal sizes of the size distribution, in an opposite trend to that induced by the presence of primary biogenic matter, according to the present study. Secondary aerosol formation is also enhanced during the high productivity periods (Yoon et al., 2007), which has been postulated to increase both total number concentration and non-sea salt sulphate mass during these periods. Oxidation of phytoplanktonproduced gaseous emissions like non-methane hydrocarbons, has been postulated to lead to secondary organic aerosol formation during high biological activity periods (Meskhidze and Nenes, 2006). These are some of the hypothetical factors that could compensate for the reduction in the size induced by the primary organic matter, leading to an overall increase in the modal sizes during high biological activity periods. Further research is therefore needed to determine what the dominant factors are that drive the seasonal evolution of the atmospheric marine aerosol size distribution.

\section{Size-resolved source flux parameterisation as a function of the diatomaceous biogenic carbon concentration}

Parameterisations of sea-spray source functions are generally formulated to estimate the sea-spray production as a function of wind speed and whitecap fraction (which in turn is formulated as function of wind speed) by using the so-called whitecap method (Lewis and Schwartz, 2004).

In order to account for the effect of the biogenic marine organic matter on the particle production, a primary sea spray source parameterisation defined as a function of seawater diatomaceous $\mathrm{OC}_{<0.2 \mu \mathrm{m}}$ concentration was derived from the presented production experiments. Although other factors such as water temperature and salinity are likely to affect the sea spray particle production (Mårtensson et al., 2003; Lewis and Schwartz, 2004), these effects are not contemplated here. The particle flux per bubble covered area can be calculated from the size distributions (based on the dry diameter $D_{p 0}$ ) by considering the bubble production (Mårtensson et al., 2003):

$$
\frac{d F_{p}}{d \log D_{p 0}}=\frac{Q}{A_{b}} \frac{d N_{T}}{d \log D_{p 0}}
$$

where $d F_{p} / d \log D_{p 0}$ is the size-resolved particle flux per unit time and water surface covered by bubbles, $\mathrm{Q}$ is the sweep air flow, $d N_{T} / d \log D_{p 0}$ is the particle size distribution and $A_{b}$, is the total surface area covered by bubbles. The calculation 
of the bubble coverage was conducted under the assumption that the bubbles burst upon reaching the water surface. It has been postulated that the presence of surfactants might affect the lifetime of bubbles on the seawater surface and, thereby, the whitecap coverage (Lewis and Schwartz, 2004). The experimental characterization of this hypothetical effect is, nevertheless, missing (Lewis and Schwartz, 2004). The area covered by bubbles was calculated by integrating the steady state bubble spectrum, considering that at equilibrium conditions, the amount of bubbles produced is equal to the amount of bubbles reaching the surface. The bubble spectrum obtained for one water jet (shown in Fig. 7) was scaled to a configuration with eight water jets. To do this, the air entrainment linked to each individual jet in the multi-jet system was calculated by using the air entrainment ratio parameterisation from Bin (1993), which yields a factor of 0.29 with respect to the air entrainment for the single water jet system. In this calculation, the bubble spectrum generated in seawater without added surfactants was employed under the assumption that the effects of surfactants on the bubble spectrum is negligible in the presence of electrolytes. This assumption is based on experiments by Asher et al. (1997), which show that the addition of surfactants to sterilised seawater does not modify the bubble spectrum generated by water impingement.

In order to account for the effect of the marine organics on the particle size distribution, the parameterisation was formulated to define the dependence of the lognormal parameters of the modes comprising the sea-spray distribution on the seawater diatomaceous $\mathrm{OC}_{<0.2 \mu \mathrm{m}}$ content. To derive the size-resolved flux source function the submicron size distribution $d N_{T} / d \log D_{p 0}$ in the $3-450 \mathrm{~nm} D_{p 0}$ range is defined as the sum of four lognormal modes:

$$
\begin{aligned}
& \frac{d N_{T}}{d \log D_{p 0}}=\sum_{i=1}^{i=4} \frac{d N_{T, i}}{d \log D_{p 0}}= \\
& =\sum_{i=1}^{i=4} \frac{N_{T, i}}{\sqrt{2 \pi} \log \sigma_{i}} \exp \left[-\frac{1}{2}\left(\frac{\log \left(D_{p 0} / D_{p 0 g, i}\right)}{\log \sigma_{i}}\right)^{2}\right]
\end{aligned}
$$

where $i$ is the subindex for the mode number and $N_{i}, D_{p 0 g, i}$ and $\sigma_{i}$ are the total particle number, geometric mean and geometric standard deviation for each lognormal mode.

The total particle number and geometric mean of the lognormal modes comprising the distributions can be parameterised as a function of the seawater $\mathrm{OC}_{<0.2 \mu \mathrm{m}}$ content by fitting equations to the data obtained in the analysis presented in Fig. 9. Using the relationships between the seawater $\mathrm{OC}_{<0.2 \mu \mathrm{m}}$ content and the particle size distribution properties, the total particle number and the geometric mean diameter can be defined by fitting 3rd order polynomial and exponential regressions to the data, respectively, in a diatomaceous $\mathrm{OC}_{<0.2 \mu \mathrm{m}}$ concentration range between 0 and $512 \mu \mathrm{M}$ :

$N_{T, i}=\beta_{i, 1}\left[\mathrm{OC}_{<0.2 \mu \mathrm{m}}\right]^{2}+\beta_{i, 2}\left[\mathrm{OC}_{<0.2 \mu \mathrm{m}}\right]+\beta_{i, 3}$
Table 5. Values of parameters inferred from polynomial and exponential regressions defining the total particle number and geometric mean diameter of the lognormal modes comprising the size distributions as a function of the diatomaceous $\mathrm{OC}_{<0.2 \mu \mathrm{m}}$ content of seawater ( $i=$ mode number).

\begin{tabular}{lrrrr}
\hline Parameter & Mode 1 & Mode 2 & Mode 3 & Mode 4 \\
\hline$\alpha_{i, 1}$ & 12.328 & 38.077 & 102.31 & 281.65 \\
$\alpha_{i, 2}$ & 2.2958 & 8.0935 & 25.251 & 46.80 \\
$\alpha_{i, 3}$ & 0.00452 & 0.00705 & 0.00080 & 0.000761 \\
$\beta_{i, 1}$ & 0.0311 & -0.031633 & 0.013154 & -0.0017762 \\
$\beta_{i, 2}$ & -13.916 & 35.73 & -9.7651 & 1.1665 \\
$\beta_{i, 3}$ & 4747.8 & 12920 & 7313.4 & 6610 \\
\hline
\end{tabular}

$D_{p 0 g, i}=\alpha_{i, 1}+\alpha_{i, 2} \exp \left(-\alpha_{i, 3}\left[\mathrm{OC}_{<0.2 \mu \mathrm{m}}\right]\right)$

The values of the parameters inferred from these regressions are included in Table 5. The geometric standard deviation values derived from the fitting procedure were 1.55 , 1.7, 1.5 and 1.7 for each of the lognormal modes (modes 1 to 4 ), in the organics-free seawater case. Only the value of the standard deviation of the second lognormal mode changed to 1.9 for the case with organics. For the rest of the modes no significant changes were observed in the geometric standard deviation with the modification of the organic concentration. Reasonable agreement between the predicted and observed particle fluxes is achieved with the fitting procedure applied, with a deviation of $\sim 40 \%$ within $95 \%$ limits for all the experiments conducted in this study (Fig. 13). For generalisation of the derived source function flux to oceanic conditions it is assumed that the open ocean aerosol flux scales with bubble coverage based on the parameterisation in terms of whitecap coverage. Under these assumptions the oceanic size-resolved particle number flux is determined by multiplying the derived size resolved flux $\left(d F_{p} / d \log D_{p 0}\right)$ by the fractional whitecap coverage, $\mathrm{W}$, as a function of wind speed:

$\frac{d F_{0}}{d \log D_{p 0}}=\frac{d F_{p}}{d \log D_{p 0}} W=\frac{Q}{A_{b}} \frac{d N_{T}}{d \log D_{p 0}} W$

where $d F_{0} / d \log D_{p}$ is the size-resolved sea-spray source flux. For determining the whitecap coveragethe formulation of Monahan and O'Muircheartaigh (1980) is applied:

$W=3.84 \times 10^{-6} U_{10}^{3.41}$

where $U_{10}$ is the wind speed at a height of $10 \mathrm{~m}$ above the sea surface. Although other whitecap coverage formulations are available in the literature (Anguelova and Webster, 2006), the equation of Monahan and O'Muircheartaigh (1980) is adopted in order to compare with size resolved fluxes estimated in other studies (Mårtensson et al., 2003; Clarke et al., 2006). The uncertainty derived from the use of the whitecap coverage estimation is discussed below. 


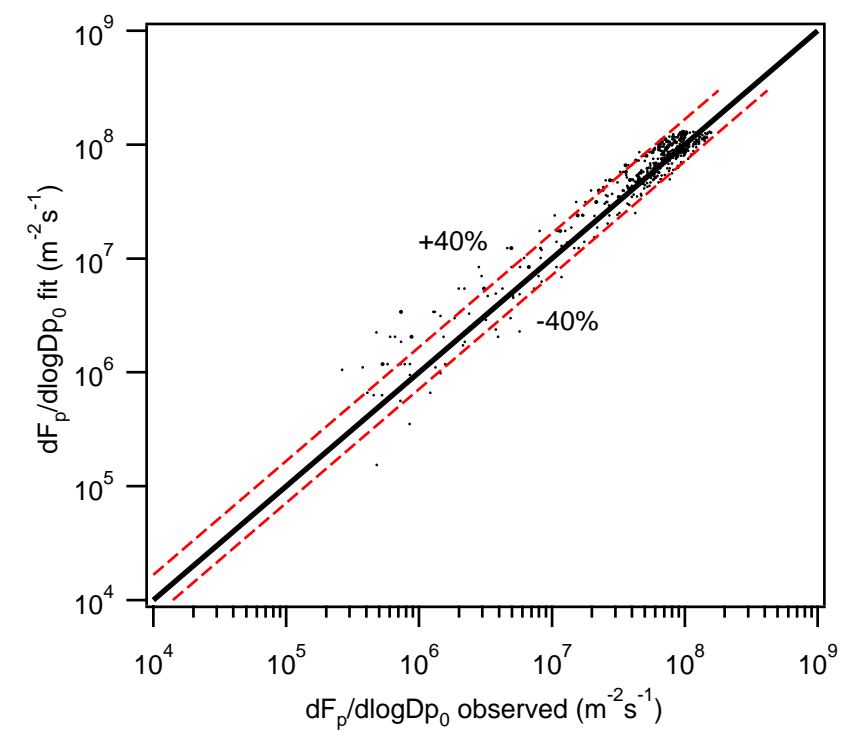

Fig. 13. Correlation between experimental and derived particle flux using the parameterisation defined by Eqs. (1-4). The relative error indicated corresponds to the maximum deviation within the $95 \%$ limits.

Figure 14 shows the size-resolved particle source flux as a function of $D_{p 0}$ derived from the proposed parameterisation and others in the literature at a wind speed of $9 \mathrm{~ms}^{-1}$. The flux estimation for the exudate-free seawater case is comparable to other parameterisations available in the submicron size range (Mårtensson et al., 2003; Clarke et al., 2006; Tyree et al., 2007). The novel source function, which extends the studied size range down to $3 \mathrm{~nm}$, is able to account for the effect of the seawater organic matter on the shape of the size resolved flux. The highest impact of the organic matter on the flux distribution is observed for particle diameters below $100 \mathrm{~nm}$. The sub-100 nm particle flux generated from seawater with $300 \mu \mathrm{M} \mathrm{OC}<0.2 \mu \mathrm{m}$ is higher than that produced from organic-free seawater with a multiplicative factor from 1.03 to 2. Particles in this size range can have an effect on the $\mathrm{CCN}$ formation. Although generally a minimum dry diameter of $80 \mathrm{~nm}$ is considered for cloud activation, observations by Clarke et al. (2006) and Murphy et al. (1998) and modelling study by Pierce et al. (2006) suggests that particles smaller than $80 \mathrm{~nm}$ can become effective CCN through heterogeneus growth and coagulation with other sub-80 nm particles. Furthermore, little is known on the effect that this organic matter can exert on the cloud activation properties of the sea-spray aerosol. Specific investigation on the cloud condensation activity of these particles is needed in order to determine the overall effect of the biogenic matter on cloud formation.

Total number source fluxes derived from the defined parameterisation as a function of wind speed are compared in Fig. 15 with other submicron formulations obtained from laboratory measurements by Mårtensson et al. (2003) and

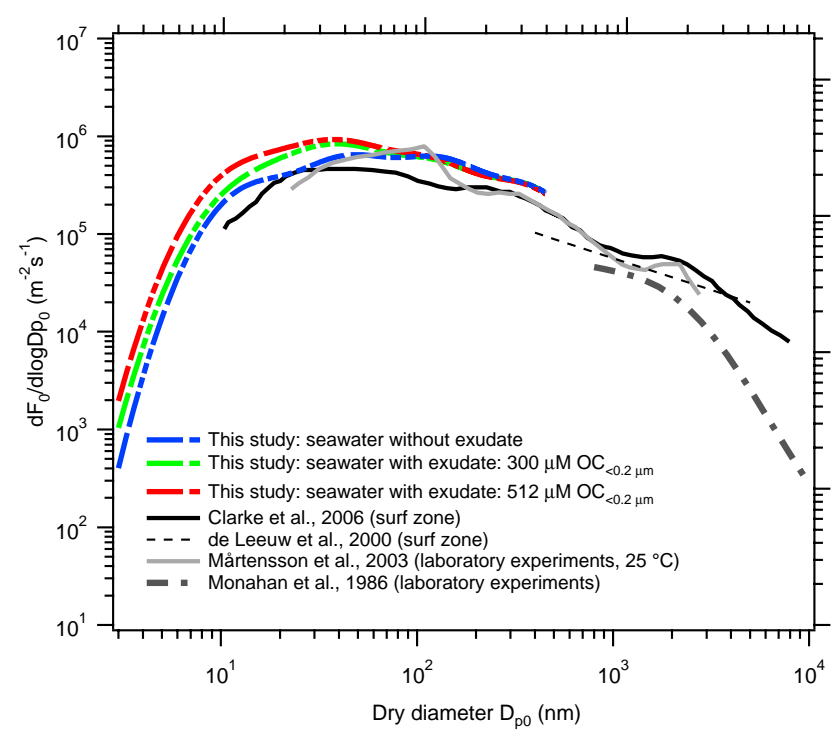

Fig. 14. Comparison of the size-resolved source flux function derived in this study at different diatomaceous $\mathrm{OC}_{<0.2 \mu \mathrm{m}}$ concentrations and other formulations available in literature $\left(U_{10}=9 \mathrm{~m} / \mathrm{s}\right)$.

field measurements by Nilsson et al. (2001) and Geever et al. (2005). The results are also compared with the standard parameterisation of Monahan et al. (1986) and de Leeuw et al. (2000), both applied in the supermicron size range. The error bars in the source function derived in this study indicate an uncertainty of $45 \%$, as derived from the variability in the particle size distribution measurements plus the mean deviation associated with the data fitting procedure. As stated by Mårtensson et al. (2003), the supermicron size range accounts for a small fraction of the total particle flux. Comparison of the supermicron flux estimated using de Leeuw et al. (2000) and the submicron flux calculated with the proposed parameterisation indicates that the supermicron flux accounts for a small fraction $(<2 \%)$ of total particle number flux. The source flux derived in this study is in agreement with the magnitude of particle fluxes estimated with other parameterisations comprising the submicron size range and particularly close to the curve of Marrtensson et al. (2003) for the case without algal exudate. According to the organic-dependent parameterisation, the presence of diatomaceous organic matter at $300 \mu \mathrm{M} \mathrm{OC}<0.2 \mu \mathrm{m}$ concentration causes an increase in the particle flux of $\sim 20 \%$ percent with respect to the case without marine surfactants.

Although the expression of Monahan and O'Muircheartaigh (1980) is commonly used for estimating the whitecap coverage, the significant scatter existing between measurements of whitecap coverage as a function of wind speed, has led to the derivation of numerous different formulations (see Anguelova and Webster (2006) for a review). The uncertainty inferred by Lewis and Schwartz (2004) from the variability associated to the 

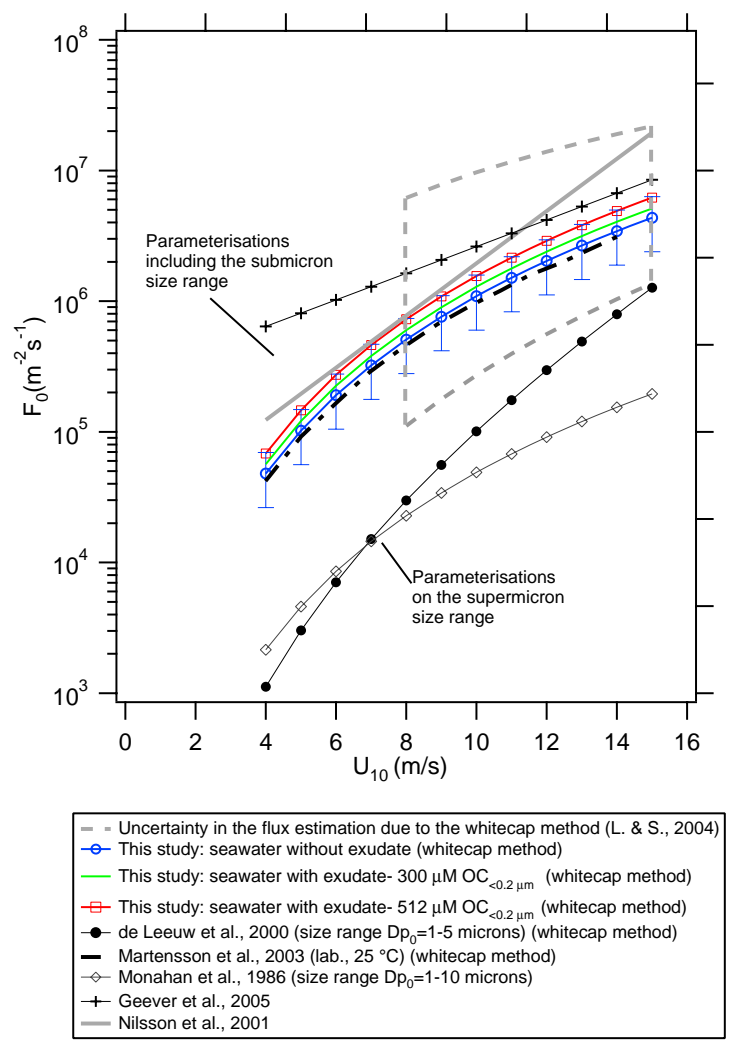

Fig. 15. Comparison of total source flux derived in this study as a function of the wind speed for organics-free seawater and seawater enriched with organic matter and other available parameterisations defined in the submicron and supermicron size regions in the literature. Error bars are included for indication of the upper and lower bounds in the particle flux determination as a result of propagation of errors through the analysis procedure.

whitecap coverage measurements obtained by photographic studies has been plotted in Fig. 15. The large scatter in the measurements of whitecap coverage indicates that factors other than wind speed play a role in the determination of the whitecap fraction. Atmospheric stability, surface temperatures, surface current velocity, wind fetch and duration, salinity and surfactant concentration can also affect sea state and whitecap formation (Anguelova and Webster, 2006). Quantification of the effects of these factors on the whitecap coverage and, specifically, the effect due to the presence of biogenic surfactants is missing. Thereby, improvement in the determination of the whitecap coverage is important for reducing the uncertainty in studies where the whitecap method is applied (Mårtensson et al., 2003; Clarke et al., 2006; Tyree et al., 2007)

Within the limitations imposed by the uncertainty associated to the determination of the whitecap fraction, the parameterisation proposed in this study would potentially constitute a useful tool for the modeling of submicron aerosol primary fluxes in the $3-450 \mathrm{~nm}$ dry diameter range.

\section{Relationship between chlorophyll- $a$ and seawater $\mathrm{OC}_{<0.2 \mu \mathrm{m}}$ concentration}

In order to facilitate the use of the presented parameterisation as a function of ocean-related data, an approximation to link chl-a diatom biomass and organic carbon production is proposed. Analysis of water-leaving radiances measured by ocean color sensors (method PhySAT, Alvain et al., 2008) and the NASA Ocean Biogeochemical Model (Gregg et al., 2003) provide estimates of the global distribution of diatom biomass in the oceans. Also, recent progress has been made on the retrieval of the chl-a diatom biomass oceanic distribution by applying the Differential Optical Absorption Spectroscopy method (PhytoDOAS) with input of phytoplankton differential absorption spectra from the satellite sensor SCIAMACHY (Bracher et al., 2009). It should be taken into account that ocean color data provide estimates rather than accurate information on the phytoplankton distribution in the oceans; however, the information derived from ocean-color products can be used as a first-order approximation of the marine biota distribution.

The origin of phytoplankton-derived organic carbon in seawater is the photosynthetic extracellular production and the liberation of cellular organic matter as a result of cell lysis (Myklestad, 2000). The mean life span of phytoplankton, considering cell mortality due to cell lysis, is $\sim 23$ days (Marbà et al., 2009), with approximately 10 days spent in the growth phase (Obernosterer and Herndl, 1995). Most of the organic matter released by phytoplankton is of labile and semilabile nature (Owaga and Tanque, 2003), which is degraded by bacteria within periods from days to several weeks.

Assuming a steady population phytoplankton population with a maximum bloom duration of the order of the typical phytoplankton lifespan (23 days), a production balance can be used as a first-order estimation of the amount of total organic matter resulting from extracellular release $\left(\mathrm{TOC}_{\text {extracell }}\right)$, cell lysis $\left(\mathrm{TOC}_{\text {lysis }}\right)$ and biodegradation $\left(\mathrm{TOC}_{\text {biodeg }}\right)$ during the algae lifetime as:

$$
\begin{aligned}
& \mathrm{TOC}=\mathrm{TOC}_{\text {extracell }}+\mathrm{TOC}_{\text {lysis }}-\mathrm{TOC}_{\text {biodeg }}= \\
& \sum_{t=1}^{t_{\text {lysis }}} \mathrm{ER}_{\mathrm{TOC}} \cdot \mathrm{f}_{\text {lysis }} \cdot \mathrm{Chl}-\mathrm{a}_{\text {diatom }}+ \\
& \sum_{t=1}^{t_{\text {grazing }}} \mathrm{ER}_{\mathrm{TOC}} \cdot\left(1-\mathrm{f}_{\text {lysis }}\right) \cdot \mathrm{Chl}-\mathrm{a}_{\text {diatom }}+ \\
& f_{\text {lysis }} \cdot \mathrm{Chl}-a_{\text {diatom }}\left[C: \text { Chl- } a_{\text {diatom }}\right]
\end{aligned}
$$

where Chl- $a_{\text {diatom }}$ is the Chl- $a$ diatom biomass concentration, $\mathrm{ER}_{\mathrm{TOC}}$ is the specific extracellular production rate $(\mu \mathrm{g} \mathrm{C}$ $\mu \mathrm{g} \mathrm{Chl}-a^{-1} \mathrm{~h}^{-1}$ ), $t_{\text {lysis }}$ and $f_{\text {lysis }}$ are the lifespan and the fraction of the biomass which dies by lysis, respectively, $t_{\text {grazing }}$ is the lifespan of algal cells removed by grazing and C:Chl$a_{\text {diatom }}$ is the carbon to Chl- $a$ mass ratio for the algal cells. 
For application of the presented balance the following aspects should be considered:

- in the ocean, the phytoplankton lifetime is likely to be reduced due to removal processes other than lysis, such as grazing and sinking below the photic layer. Due to diverging findings on the rate of phytoplankton death by lysis in the ocean, there is no general agreement on the main process leading to phytoplankton death, and thereby, its lifespan in the oceans (Kirchman, 1999). For example, lysis has been shown to account for $75 \%$ of phytoplankton death at the end of a spring bloom in the North Sea (Brussaard et al., 1995), whereas in the Pacific Ocean, phytoplankton growth is roughly matched by grazing (Landry, 1997). Loss of phytoplankton by grazing and sinking has an effect on the amount of organic matter released, since removal of the cells before completion of their life cycle will lead to lower excretion of organics to the medium. For applying Eq. (7), the results were evaluated in the extreme cases of 0.1 and 1 for $f_{\text {lysis }}$ and 0.5 and 23 days for the grazed phytoplankton lifetime ( $t_{\text {grazing }}$ ).

- mean net extracellular production rates for diatoms and other algal species are on the order of $0.34 \mu \mathrm{mol} \mathrm{C} \mu \mathrm{g}$ $\mathrm{Chl}-a^{-1} \mathrm{~h}^{-1}$ and $0.089 \mu \mathrm{mol} \mathrm{C} \mu \mathrm{g} \mathrm{Chl}-a^{-1} \mathrm{~h}^{-1} \mathrm{C}$ at the growth (10 days) and steady state phases (13 days), respectively. These rates were determined in an experimental mesocosm with a diatom culture and bacterial activity at different nutrient conditions, where the extracellular release was found to be $\sim 20 \%$ of the total photosynthetic production (Obernosterer and Herndl, 1995). Thus, these rates represent the net production of organic carbon balanced for bacterial degradation.

- The complex effects of light, nutrients and temperature lead to a highly variable $\mathrm{C}$ : Chl- $a$ mass ratio in phytoplankton cells (Geider, 1987; Clark, 2001). Ratios as low as 12 (Bunt and Lee, 1970) to maximum values $\sim 500$ (Smith et al., 1985) have been observed in algal blooms in the ocean. Some approaches have been proposed to parametrise the C:Chl- $a$ ratio as a function of irradiance, nitrate, iron, and temperature (Wang et al., 2009). In order to account for this large variation, equation 7 was evaluated for the maximum and minimum $\mathrm{C}: \mathrm{Chl}-\mathrm{a}$ ratio values reported in the literature.

The variation of the above described parameters within their known limit values, together with the assumption that $\mathrm{OC}_{<0.2 \mu \mathrm{m}}$ accounts for $\sim 80 \%$ of the total organic matter (TOC) (Kepkay, 2000), yield a relationship between Chl- $a$ diatom biomass and diatomaceous $\mathrm{OC}_{<0.2 \mu \mathrm{m}}$ defined by the dashed area in Fig. 16. The magnitude of the region in the plot indicates that substantial variations in the Chla-seawater OC relationship are expected depending on the lysis to grazing ratio, lifetime of grazed cells ( $\left.t_{\text {grazing }}\right)$ and environmen-

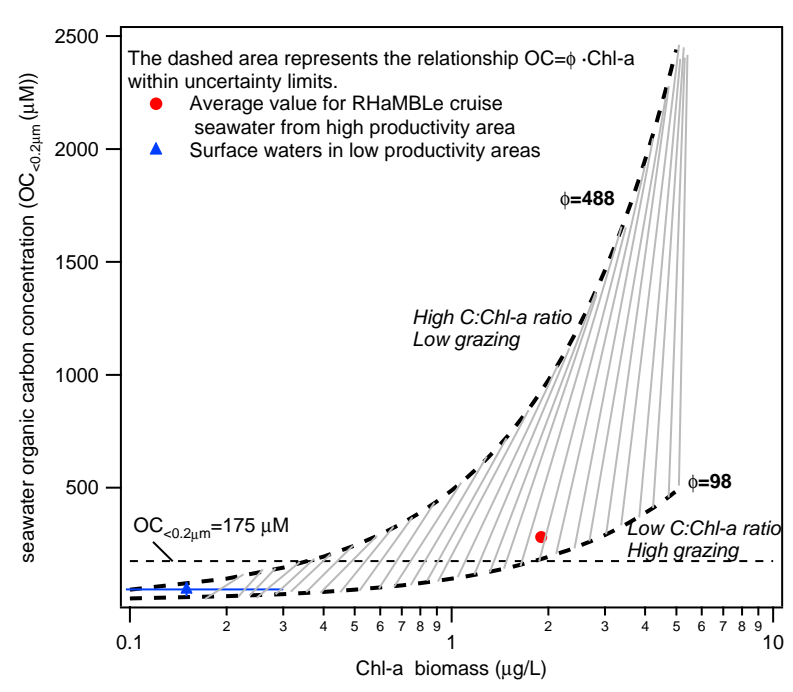

Fig. 16. The dashed area represents the relationship between Chl- $a$ and seawater $\mathrm{OC}_{<0.2 \mu \mathrm{m}}$ concentration, as obtained from the variation of the parameters defined in Eq. (7). The magnitude of the region indicates that the relationship is highly dependent on the specific conditions of the algal bloom, i.e., C:Chla ratio, grazing rate and lifespan of phytoplankton cells. The data provided for low biological activity areas is defined considering SeaWiFFs Chl$a$ data and seawater organic carbon concentrations from Owaga and Tanque (2003). The horizontal dashed line at $\mathrm{OC}_{<0.2 \mu \mathrm{m}}=175 \mu \mathrm{M}$ indicates that an impact of the biological activity on primary particle fluxes is likely to occur for diatom Chl- $a$ biomass concentrations $>0.35-2 \mu \mathrm{g} / \mathrm{L}$, depending on the specific conditions in the algal bloom.

tal conditions that determine the $\mathrm{C}$ : Chl- $a$ mass ratio. In order to numerically illustrate the sensitivity of the calculated $\mathrm{OC}_{<0.2 \mu \mathrm{m}}$ to these factors, Table 6 presents the $\mathrm{OC}_{<0.2 \mu \mathrm{m}}$ percent variation as a result of a $40 \%$ change in these parameters. The variable relationship between Chl- $a$ and organic matter production suggests that the organic mass fraction in primary particles might not be only a function of the Chl- $a$ concentration (O'Dowd et al., 2008) and that the particle organic enrichment depends on the specific conditions for production of organic matter in algal blooms. In such a case, a regional relationship between Chl- $a$ concentration and organic particle fraction could not be extrapolated to a global scale. Further study is therefore needed in order to assess the relationship between primary particle organic enrichment and marine biological activity.

In the experiments in these study it was shown that concentrations of seawater diatomaceous $\mathrm{OC}_{<0.2 \mu \mathrm{m}}>175 \mu \mathrm{M}$ produced an effect on the particle production. Figure 16 indicates that this organic carbon concentration corresponds to a Chl- $a_{\text {diatom }}$ biomass $>0.35-2 \mu \mathrm{g} / \mathrm{l}$, depending on the primary organics specific production. A lower concentration of Chl$a$ is required to produce high $\mathrm{OC}_{<0.2 \mu \mathrm{m}}$ in areas with high $\mathrm{C}$ :Chl- $a$ ratio and low grazing, as at these conditions the lifespan of the cells is long and the production of $\mathrm{C}$ per unit 
Table 6. Sensitivity of $\mathrm{OC}_{<0.2 \mu \mathrm{m}}$ concentrations estimated with Eq. (7) to $40 \%$ variations in $f_{\text {lysis }}, t_{\text {grazing }}$ and C:Chl- $a$ ratio ( $x=$ parameter).

\begin{tabular}{lrrr}
\hline Parameter & $f_{\text {lysis }}$ & $t_{\text {grazing }}$ & C:Chl- $a$ ratio \\
\hline$\Delta x(\%)$ & 40 & 40 & 40 \\
$\Delta \mathrm{OC}_{<0.2 \mu \mathrm{m}(\%)}$ & 35 & 1.42 & 33 \\
\hline
\end{tabular}

mass of Chl- $a$ is high. The requirement of Chl- $a$ concentration $>0.35-2 \mu \mathrm{g} / \mathrm{L}$ to reach organic concentrations $>175 \mu \mathrm{M}$ $\mathrm{OC}_{<0.2 \mu \mathrm{m}}$ indicate that an impact of the biological activity on particle production is likely to occur in diatom algal blooms. There is evidence that levels of diatom biomass can be as high as $2 \mu \mathrm{g} / \mathrm{l}$ in bloom regions (Bracher et al., 2009). Furthermore, remote sensing analysis has shown that areas of high Chl- $a$ biomass in the ocean are mostly associated with high concentration of diatoms and that large scale diatom blooms are formed in warm periods (Alvain et al., 2005).

The combination of Eq. (7) with the regressions defined by Eqs. (3) and (4), provides a parameterisation of the primary particle flux as a function of the Chl- $a$ diatom biomass, applicable in warm waters with low to high biological activity. This parameterisation complements the formulation presented by Mårtensson et al. (2003), which considered the effect of temperature on particle production, by additionally including the influence of the primary organic matter on the particle production. It should be noted that the approach applied here to determine the Chl- $a$ and $\mathrm{OC}_{<0.2 \mu \mathrm{m}}$ relationship does not account for factors like hydrological transport of organic matter, which could affect the organic carbon distribution with respect to the Chl- $a$ biomass concentration in the ocean. The presented approach constitutes a first order empirical estimation of the relationship between $\mathrm{OC}_{<0.2 \mu \mathrm{m}}$ and Chl- $a$ biomass in algal blooms. Thus, further research is needed is order to model the $\mathrm{OC}_{<0.2 \mu \mathrm{m}}$ and Chl- $a$ biomass relationship with improved accuracy, if ocean color data is to be applied.

\section{$7 \quad$ Summary and conclusions}

In this study, the effect of phytoplankton-derived organics on the production of primary marine aerosol has been analysed. Seawater samples were collected along a transect off the West African coast (RRS Discovery D319, RHaMBLe cruise) during a high biological activity period in order to identify the dominant oceanic algal species. Cultures of microalgal strains representative of oceanic species found in the collected oceanic waters were grown in order to produce natural bioexudate, which was employed as marine organic matter proxy for the performance of laboratory marine aerosol characterization. The process of formation of marine aerosol via bubble-bursting was simulated by the impingement of liquid plunging-waterjets generated by a recirculation system. Different organic monolayers and seawater proxies enriched with diatomaceous and nanoplankton exudate were prepared for the laboratory production of marine aerosol. The submicron aerosol size distribution $(3 \mathrm{~nm}-450 \mathrm{~nm}$ dry diameter) of the formed aerosol was characterised for different organic concentrations and algal exudates in the seawater samples.

A shift of the sub-micron size distribution to smaller sizes and an increase in the number of particles $<100 \mathrm{~nm}$ (dry diameter) was observed when the exudates of the diatomaceous species were mixed in the seawater bulk, with respect to the production from artificial seawater without exudate. Decomposition of the aerosol size distributions into lognormal modes indicated that the effect produced on the size distribution is due to an increase in the production of particles of a lognormal mode with modal size $\sim 45 \mathrm{~nm}$ and a reduction in the production of particles of a lognormal mode centered at $\sim 125 \mathrm{~nm}$ with increasing organic matter concentration in seawater. The reduction of the modal sizes of the lognormal modes comprising these distributions contributed to this effect. These trends were in agreement with analogous size distribution measurements conducted with oceanic unfiltered seawater samples collected from productive and non-productive waters along the RHaMBLe cruise transect route. The observed influence was found to be sensitive to the organic carbon concentration in seawater, with a diatomaceous exudate concentration between $175 \mu \mathrm{M}$ and $300 \mu \mathrm{M}$ $\mathrm{OC}_{<0.2 \mu \mathrm{m}}$ required to observe a significant impact on the particle production. Given that the average concentration of organic matter in oceanic surface waters is within the range $50-80 \mu \mathrm{M} \mathrm{OC}_{<0.5-0.7 \mu \mathrm{m}}$ (Owaga and Tanque, 2003), this influence is expected only to be significant in areas of high biological activity, where $\mathrm{OC}_{<0.2 \mu \mathrm{m}}$ values higher than $300 \mu \mathrm{M}$ can be found. The results obtained in the present study indicate that interpretation and comparison of independent studies should be made considering that the effect of the marine organic matter on the aerosol primary production depends on the seawater organic content and the dominant algal species producing the marine exudate.

A size-resolved source flux function, including an explicit term to account for the seawater diatomaceous organic concentration, was derived from the size distribution measurements by using the whitecap method. This parameterisation is applicable in the 3-450 $\mathrm{nm}$ dry diameter size range for between $0-512 \mu \mathrm{M} \mathrm{OC}<0.2 \mu \mathrm{m}$ of diatomaceous origin. A diatomaceous exudate concentration of $300 \mu \mathrm{M} \mathrm{OC}_{<0.2 \mu \mathrm{m}}$ produces an overall increment in the total source particle flux of about $20 \%$, with a multiplicative factor between 1.03 and 2 for the flux of particles $<100 \mathrm{~nm}$, with respect to the exudatefree seawater case.

The impact of the organic matter on the production of particles below $100 \mathrm{~nm}$ can have an effect on the CCN formation, particularly if sub- $80 \mathrm{~nm}$ particles are considered 
potential precursors of cloud condensation nuclei (Clarke et al., 2006; Murphy et al., 1998; Pierce et al., 2006). Although the cloud condensation activity over algal bloom areas has been postulated to be related to secondary aerosol formation from phytoplankton-produced gaseous emissions (Charlson et al., 1987; Meskhidze and Nenes, 2006), it is unknown whether the presence of primary organics in the sea-spray aerosol might have an impact on the particles $\mathrm{CCN}$ activation properties. Specific investigation on the cloud condensation activity of these particles is needed in order to determine the overall effect of the biogenic organic matter on cloud formation. Further research aiming to clarify this aspect has been conducted and will be presented as a second part of the present study.

\section{Supplementary material related to this article is available online at:

Acknowledgements. This work was supported by the UK Natural Environment Research Council [grant numbers NE/D005175/1 and NE/G000247/1].

Edited by: A. Pszenny

\section{References}

Abo Riziq, A., Erlick, C., Dinar, E., and Rudich, Y.: Optical properties of absorbing and non-absorbing aerosols retrieved by cavity ring down (CRD) spectroscopy, Atmos. Chem. Phys., 7, 15231536, doi:10.5194/acp-7-1523-2007, 2007.

Alvain, S., Moulin, C., Danndonneau, Y., and Breon, F. M.: Remote Sensing of phytoplankton groups on case 1 waters from global SeaWiFS imagery, Deep Sea Res. I, 52, 1989-2004, 2005.

Alvain, S., Moulin, C., Danndonneau, Y., and Loisel, H.: Seasonal distribution and succession of dominant phytoplankton groups in the global ocean: A satellite view, Global Biogeochem. Cy., 22, GB3001, doi:10.1029/2007GB003154, 2008.

Aluwihare, L. I. and Repeta, D. J.: A comparison of the chemical characteristics of oceanic DOM and extracellular DOM produced by marine algae, Mar. Ecol. Prog. Ser., 186, 105-117, 1999.

Alvarez-Salgado X. A. and Miller, A. E. J.: Simultaneous determination of dissolved organic carbon and total dissolved nitrogen in seawater by high temperature catalytic oxidation: conditions for precise shipboard measurements, Mar. Chem., 62, 325-333, 1998.

Anguelova, M., Barber, R. P., and Wu, J.: Spume Drops Produced by the Wind Tearing of Wave Crests, J. Phys. Oceanogr., 29(6), 1156-1165, 1999.

Anguelova, M. D. and Webster, F.: Whitecap coverage from satellite measurements: A first step toward modeling the variability of oceanic whitecaps, J. Geophys. Res., 111, C03017, doi:10.1029/2005JC003158, 2006.

Asher, W. E., Karle, L. M., and Higgins, B. J.: On the differences between bubble-mediated air-water transfer in freshwater and seawater, J. Mar. Res., 55, 813-845, 1997.
Batchelor, G. K.: An Introduction to Fluid Dynamics, Cambridge University Press, Cambridge, 1967.

Bin, A. K.: Gas entrainment by plunging liquid jets, Chem. Eng. Sc., 48(21), 3585-3630, 1993.

Boulton-Stone, J. M.: The effect of surfactant on bursting gas bubbles, J. Fluid Mech., 302, 231-257, 1995.

Braban, C. F, Adams, J. W., Rodriguez, D.,Cox, R. E., Crowley, J. N., and Schuster, G.: Heterogeneous reactions of HOI, ICl and IBr on sea salt and sea salt proxies, Phys. Chem. Chem. Phys., 9, 3136-3148, 2007.

Bracher, A., Vountas, M., Dinter, T., Burrows, J. P., Röttgers, R., and Peeken, I.: Quantitative observation of cyanobacteria and diatoms from space using PhytoDOAS on SCIAMACHY data, Biogeosciences, 6, 751-764, doi:10.5194/bg-6-751-2009, 2009.

Bunt J. S. and Lee, C. C.: Seasonal primary production in the Antarctic sea ice at McMurdo Sound in 1967, J. Mar. Res., 28, 304-320, 1970.

Brussaard, C. P. D., Riegman, R., Noordeloos, A. A. M., Cadee, G. C., Witte, H., Kop, A. J., Nieuwland, G., Van Duyl, F. C., and Bak, R. P. M.: Effects of grazing, sedimentation and phytoplankton cell lysis on the structure of a coastal pelagic food web, Mar. Ecol. Prog. Ser., 123, 259-271, 1995.

Cavalli, F., Facchini, M. C., Decesari, S., Mircea, M., Emblico, L., Fuzzi, S., Ceburnis, D., Yoon, Y. J., O’Dowd, C. D., Putaud, J. P., and Dell'Acqua, A. J.: Advances in characterization of sizeresolvedorganic matter in marine aerosol over the North Atlantic, Geophys. Res., 109(D24),D24215, doi:10.1029/2004JD005137, 2004.

Ceburnis, D., O’Dowd, C. D., Jennings, G. S., Facchini, M. C., Emblico, L., Decesari, S., Fuzzi, S., and Sakalys, J.: Marine aerosol chemistry gradients: Elucidating primary and secondary processes and fluxes, Geophys. Res. Lett., 35, L07804, doi:10.1029/2008GL033462, 2008.

Charlson, R. J., Lovelock, J. E., Andreae, M. O., and Warren, S. G.: Oceanic phytoplankton, atmospheric sulphur, cloud albedo and climate, Nature, 326, 655, 655-661, 1987.

Cipriano, R. J. and Blanchard, D.: Bubble and Aerosol Spectra Produced by a Laboratory 'Breaking Wave', J. Geophys. Res., 86(C9), 8085-8092, 1981.

Clark, D. R.: Growth rate relationships to physiological indices of nutrient status in marine diatoms, J. Phycol., 37(2), 249-256, 2001.

Clarke, A. D., Owens, S. R., and Zhou, J.: An ultrafine sea-salt flux from breaking waves: Implications for cloud condensation nuclei in the remote marine atmosphere, J. Geophys. Res., 111, D06202, doi:10.1029/2005JD006565, 2006.

Cloke, J., McKay, W. A., and Liss, P. S.: Laboratory investigations into the effect of marine organic material on the sea-salt aerosol generated by bubble bursting, Marine Chem., 34, 77-95, 1991.

de Leeuw, G., Neele, F. P., Hill, M., Smith, M. H., and Vignali, E.: Production of sea spray aerosol in the surf zone, J. Geophys. Res., 105(D24), 29397-29409, 2000.

Dey, D., Boulton-Stone, J. M., Emery, A. N., and Blake, J. R.: Experimental comparisons with a numerical model of surfactant effects on the burst of a single bubble, Chem. Eng. Sci., 52(16), 2769-2783, 1997.

Duce, R. A. and Hoffman, E. J.: Chemical fractionation at the air/sea interface, Annu. Rev. Earth Planet. Sci., 4, 187-228, 1976. 
Facchini, M. C., Rinaldi, M., Decesari, S., Carbone, C., Finessi, E., Mircea, M., Fuzzi, S., Ceburnis, D., Flanagan, R., Nilsson, E. D, de Leeuw, G., Martino, M.,Woeltjen, J., and O'Dowd, C. D.: Primary submicron marine aerosol dominated by insoluble organic colloids and aggregates, Geophys. Res. Lett., 35, L17814, doi:10.1029/2008GL034210, 2008.

Fitzgerald J. W.: Marine aerosols: a review, Atmos. Environ., ZSA, 533-546, 1991.

Fuentes, E., Coe, H., Green, D., de Leeuw, G., and McFiggans, G.: Laboratory-generated primary marine aerosol via bubblebursting and atomization, Atmos. Meas. Tech., 3, 141-162, doi:10.5194/amt-3-141-2010, 2010.

Geider, R. J.: Light and temperature dependence of the carbon to chlorophyll a ratio in microalgae and cyanobacteria: implications for physiology and growth of phytoplankton, New Phytol., 106, 1-34, 1987.

Geever, M., O’Dowd, C., van Ekeren, S., Flanagan, R., Nilsson, D., de Leeuw, G., and Rannik, U.: Sub-micron sea-spray fluxes, Geophys. Res. Lett., 32, L15810 doi:10.1029/2005GL023081, 2005.

Gregg, W. W., Ginoux, P., Schopf, P. S., and Casey, N. W.: Phytoplankton and iron: validation of a global three-dimensional ocean biogeochemical model, Deep Sea Res. II, 50, 3147-3169, 2003

Guillard, R. R. L.: Culture of phytoplankton for feeding marine invertebrates, edited by: Smith, W. L. and Chanley, M. H., Culture of Marine Invertebrate Animals, Plenum Press, New York, 2660, 1975.

Hoffman, E. J. and Duce, R. A.: Organic carbon in marine atmospheric particulate matter: concentration and particle size distribution, Geophys. Res. Lett., 4, 449-452, 1977.

Hultin, K. A. H., Nilsson, E. D., Krejci, R., Mårtensson, E. M., Hagstrom, A., and de Leeuw, G.: In situ laboratory sea spray production during the MAP 2006 cruise on the North East Atlantic, J. Geophys. Res., 115, D06201, doi:10.1029/2009JD012522, 2009.

Ittekot, V.: Variations of dissolved organic matter during a plankton bloom: qualitative aspects, based on sugar and amino acid analyses, Mar. Chem., 11, 143-158, 1982.

Keene, W. C., Maring, H., Maben, J. R., Kieber, D. J., Pszenny, A. A. P., Dahl, E. E., Izaguirre, M. A., Davis, A. J., Long, M. S., Zhou, X., Smoydzin L., and Sander, R.: Chemical and physical characteristics of nascent aerosols produced by bursting bubbles at a model air-sea interface, J. Geophys. Res., 112, D21202, doi:10.1029/2007JD008464, 2007.

Kepkay P. E.: Colloids in the ocean carbon cycle, in: The Handbook of Environmental Chemistry, 5, D Marine Chemistr, edited by: Wangersky, P., 35-56, Springer, Berlin, 2000.

Kester, D. R., Duedall, I. W., Conners, D. N., and Pytkowicz, R. M.: Preparation of artificial seawater, Limnol. Oceanogr., 12, 176179, 1967.

Kirchman, D. L.: Phytoplankton death in the sea, Nature, 398, $293-$ 294, 1999.

Landry, M. R., Barber, R. T., Bidigare, R. R., Chai, F., Coale, K. H., Dam, H. G., Lewis, M. R., Lindley, S. T., McCarthy, J. J., Roman, M. R., Stoecker, D. K, Verity, P. G., and White, J. R.: Iron and grazing constraints on primary production in the central equatorial Pacific: An EqPac synthesis, Limnol. Oceanogr., 42, 405-418, 1997.

Latham, J. and Smith, M. H.: Effect on global warming of wind- dependent aerosol generation at the ocean surface, Nature, 347, 372-373, 1990.

Lavender, S. J., Raitsos, D. E., and Pradhan, Y.: Variations in the Phytoplankton of the North-Eastern Atlantic Ocean: From the Irish Sea to the Bay of Biscay, Remote Sensing of the European Seas, edited by: Barale, V. and Gade, M., Springer (The Netherlands), 512-532, doi:10.1007/978-1-4020-6772-3, 2008.

Lee, J. D., McFiggans, G., Allan, J. D., Baker, A. R., Ball, S. M., Benton, A. K., Carpenter, L. J., Commane, R., Finley, B. D., Evans, M., Fuentes, E., Furneaux, K., Goddard, A., Good, N., Hamilton, J. F., Heard, D. E., Herrmann, H., Hollingsworth, A., Hopkins, J. R., Ingham, T., Irwin, M., Jones, C. E., Jones, R. L., Keene, W. C., Lawler, M. J., Lehmann, S., Lewis, A. C., Long, M. S., Mahajan, A., Methven, J., Moller, S. J., Müller, K., Müller, T., Niedermeier, N., O’Doherty, S., Oetjen, H., Plane, J. M. C., Pszenny, A. A. P., Read, K. A., Saiz-Lopez, A., Saltzman, E. S., Sander, R., von Glasow, R., Whalley, L., Wiedensohler, A., and Young, D.: Reactive Halogens in the Marine Boundary Layer (RHaMBLe): the tropical North Atlantic experiments, Atmos. Chem. Phys., 10, 1031-1055, doi:10.5194/acp-10-10312010, 2010.

Lewis, E. R. and Schwartz, S. E.: Sea Salt Aerosol Production: Mechanisms, Methods, Measurements and Models, Geophys. Monogr. Ser., vol. 152, 413 pp., AGU, Washington, DC, 2004.

Marbà, N., Duarte, C. M., and Agusti, S.: Allometric scaling of plant life history, P. Natl. Acad. Sci., 104(40), 15777-15780, 2007.

Mårtensson, E. M., Nilsson, E. D., Cohen, L. H., and de Leeuw, G.: Laboratory simulations and parameterization of the primary marine aerosol production, J. Geophys. Res., 108(D9), 4297, doi:10.1029/2002JD002263, 2003.

McNeill, V. F., Patterson, J., Wolfe, G. M., and Thornton, J. A.: The effect of varying levels of surfactant on the reactive uptake of $\mathrm{N}_{2} \mathrm{O}_{5}$ to aqueous aerosol, Atmos. Chem. Phys., 6, 1635-1644, doi:10.5194/acp-6-1635-2006, 2006.

Meskhidze, N. and Nenes, A.: Phytoplankton and cloudiness in the Southern Ocean, Science, 314(5804), 1419-1423, 2006.

Middlebrook, A. M., Murphy, D. M., and Thomson, D. S.: Observation of organic material in individual particles at Cape Grim during the First Aerosol Characterization Experiment (ACE 1), J. Geophys. Res., 103, 16475-16483, 1998.

Monahan, E. C. and O'Muircheartaigh, I.: Optimal power-law description of oceanic whitecap coverage dependence on wind speed, J. Phys. Oceanogr., 10, 2094-2099, 1980.

Monahan, E. C., Spiel, D. E., and Davidson, K. L.: A model of marine aerosol generation via whitecaps and wave disruption, in: Oceanic Whitecaps, edited by: Monahan, E. C. and MacNiochaill, G., 167-193, D. Reidel, Norwell, Mass., 1986.

Morgan, J. D., Napper, D. H., Warr, G. G., and Nicol, S. K.: Kinetics of recovery of hexadecyltrimethylammonium bromide by flotation, Langmuir, 8, 2124-2129, 1992.

Murphy, D. M., Anderson, J. R., Quinn, P. K., McInnes, L. M. Brechtel,F. J. Kreidenweis, S. M. Middlebrook, A. M. Posfai, M. Thomson, D. S., and Buseck, P. R.: Influence of sea-salt on aerosol radiative properties in the Southern Ocean marine boundary layer, Nature, 392(6671), 62-65, 1998.

Myklestad, S. M.: Dissolved organic carbon from phytoplankton. p. 111148. In The Handbook of Environmental Chemistry, Vol. 5, Part D, Mar. Chem., edited by: Wangersky, P., Springer-Verlag 
Berlin/Heidelberg, Heidelberg, 2000.

Niedermeier, D., Wex, H., Voigtländer, J., Stratmann, F., Brüggemann, E., Kiselev, A., Henk, H., and Heintzenberg, J.: LACIS-measurements and parameterization of sea-salt particle hygroscopic growth and activation, Atmos. Chem. Phys., 8, 579590, doi:10.5194/acp-8-579-2008, 2008.

Nilsson, E. D., Rannik, U., Swietlicki, E., Leck, C., Aalto, P. P., Zhou, J., and Norman, M.: Turbulent aerosol fluxes over the Arctic Ocean 2, Wind-driven sources from the sea, J. Geophys. Res., 106, 32111-32124, 2001.

Novakov, T., Corrigan, C. E., Penner, J. E., Chuang, C. C., Rosario, O., and Mayol-Bracero, O. L: Organic aerosols in the Caribbean trade winds: A natural source?, J. Geophys. Res., 102, 2130721313, 1997.

Obernosterer, I. and Herndl, G. J.: Phytoplankton extracellular release and bacterial growth: dependence on the N:P ratio, Mar. Ecol. Prog. Ser., 116, 247-257, 1995.

O’Dowd, C. D., Smith, M. H., Consterdine, I. E., and Lowe, J. A.: Marine aerosol, sea-salt, and the marine sulphur cycle: a short review, Atmos. Environ., 31, 73-80, 1997.

O’Dowd, C. D., Facchini, M. C., Cavalli, F., Ceburnis, D., Mircea, M., Decesari, S., Fuzzi, S., Yoon, Y. J., and Putaud, J.-P.: Biogenically driven organic contribution to marine aerosol, Nature, 431(7009), 676-680, 2004.

O'Dowd, C. D. and de Leeuw, G.: Marine aerosol production: a review of the current knowledge, Philos. T. Roy. Soc., 365, 20072043, 2007.

O’Dowd, C., Langmann, B., Varghese, S., Scannell, C., Ceburnis, D., and Facchini, M. C.: A combined organic-inorganic sea-spray source function, Geophys. Res. Lett., 35, L01801, doi:10.1029/2007GL030331, 2008.

Owaga, H. and Tanque, E.: Dissolved organic Matter in oceanic Waters, J. Oceanogr., 59, 129-147, 2003.

Parsons, T. R., Maita, Y., and Lalli, C. M.: Plant pigments, in: manual of chemical and biological methods for seawater analysis, edited by: Parsons, T. R., Maita, Y., and Lalli, C. M., A. Pergamon, Oxford, 99-112, 1984.

Pierce, J. R. and Adams, P. J.: Global evaluation of CCN formation by direct emission of sea salt and growth of ultrafine sea salt, J. Geophys. Res., 111, D06203, doi:10.1029/2005JD006186, 2006.

Putaud, J. P., Van Dingenen, R., Mangoni, M., Virkkula, A., Raes, F., Maring, H., Prospero, J. M., Swietlicki, E., Berg, O. H., Hillamo, R., and Makela, T.: Chemical mass closure and assessment of the origin of the submicron aerosol in the marine boundary layer and the free troposphere at Tenerife during ACE2, Tellus B, 52, 141-168, 2000.

Rapp, R. J. and Melville, W. K.,: Laboratory measurements of deepwater breaking waves, Philos. T. Roy. Soc. London A, 331, 735800, 1990.

Saul, T. D., Tolocka, M. P., and Johnston, M. V.: Reactive uptake of nitric acid onto sodium chloride aerosols across a wide range of relative humidities, J. Phys. Chem. A, 110, 7614-7620, 2006.

Sellegri, K, O’Dowd, C. D., Yoon, Y. J, Jennings, S. G., and de Leeuw, G.: Surfactants and submicron sea spray generation, J. Geophys. Res., 111, D22215, doi:10.1029/2005JD006658, 2006.

Smith, J. C., Platt, T., Li, W. K. W., Horne, E. P. W., Harrisonn, W. G., Subba Rao, D. V. and Irwin, B. D.: Arctic marine photoautotrophic picoplankton, Mar. Ecol. Prog. Ser., 20, 207-220, 1985.
Spiel, D. E.: A hypothesis concerning the peak in film drop formation as a function of bubble size, J. Geophys. Res., 102, 11531161, 1997.

Svenningsson, B., Rissler, J., Swietlicki, E., Mircea, M., Bilde, M., Facchini, M. C., Decesari, S., Fuzzi, S., Zhou, J., Mønster, J., and Rosenørn, T.: Hygroscopic growth and critical supersaturations for mixed aerosol particles of inorganic and organic compounds of atmospheric relevance, Atmos. Chem. Phys., 6, 1937-1952, doi:10.5194/acp-6-1937-2006, 2006.

Taketani, F., Kanaya Y., and Akimoto, H.: Heterogeneous loss of $\mathrm{HO}_{2}$ by $\mathrm{KCl}$, synthetic sea salt, and natural seawater aerosol particles, Atmos. Environ., 43(9), 1660-1665, 2009.

Tang, I. N., Tridico, A. C., and Fung, K. H.: Thermodynamical and optical properties of sea salt aerosols, J. Geophys. Res., 102, 23269-23275, 1997.

Tseng, R., Viechnicki, J. T., Skop, R. A., and Brown, J. W.: Seato Air transfer of surface active organic compounds by bubble bursting bubbles, J. Geophys. Res., 97, 5201-5206, 1992.

Tyree, C. A., Hellion, V. M., Alexandrova, O. A., and Allen, J. O.: Foam droplets generated from natural and artificial seawaters, J. Geophys. Res., 112, D12204, doi:10.1029/2006JD007729, 2007.

Verdugo, P., Alldredge, A. L., Azam, F., Kirchmam, D. L., Passow, U., and Santschi, P. H.: The oceanic gel phase: A bridge in the DOM-POM continuum, Mar. Chem., 92, 67-85, 2004.

Wang, X. J., Behrenfeld, M., Le Borgne, R., Murtugudde, R., and Boss, E.: Regulation of phytoplankton carbon to chlorophyll ratio by light, nutrients and temperature in the Equatorial $\mathrm{Pa}$ cific Ocean: a basin-scale model, Biogeosciences, 6, 391-404, doi:10.5194/bg-6-391-2009, 2009.

Wells, M. L. and Goldberg, E. D.: Colloid aggregation in seawater, Mar. Chem., 41(4), 353-358, 1993.

Williams, P. I.: Construction and validation of a DMPS for aerosol characterisation, University of Manchester, PhD Thesis, 1999.

Williams, P. I., McFiggans, G., and Gallagher, M. W.: Latitudinal aerosol size distribution variation in the Eastern Atlantic Ocean measured aboard the FS-Polarstern, Atmos. Chem. Phys., 7, 2563-2573, doi:10.5194/acp-7-2563-2007, 2007.

Wise, M. E., Freney, E. J., Tyree, C. A., Allen, J. O., Martin, S. T., Russel, L. M., and Buseck, P. R.: Hygroscopic behaviour and liquid-layer composition of aerosol particles generated from natural and artificial seawater, J. Geophys. Res., 114, D03201, doi:10.1029/2008JD010449, 2009.

Wolter, K.: Bacterial incorporation of organic substances by natural phytoplankton populations, Mar. Ecol. Prog. Ser., 7, 287-295, 1982.

Wu, J.: Jet Drops Produced by Bubbles Bursting at the Surface of Seawater, J. Phys. Ocean., 32, 3286-3290, 2002.

Xu, Q., Nakajima, M., Ichikawa, S., Nakamura, N., Roy, P., Okadome, H., and Shiina, T.: Effects of surfactant and electrolyte concentrations on bubble formation and Stabilization, J. Col. Int. Sci., 332, 208-214, 2009.

Yoon, Y. J., Ceburnis, D., Cavalli, F., Jourdan, O., Putaud, J. P., Facchini, M. C., Decesari, S., Fuzzi, S., Sellegri, K., Jennings, S. G., and O'Dowd, C. D.: Seasonal characteristics of the physicochemical properties of North Atlantic marine atmospheric aerosols, J. Geophys. Res., 112, D04206, doi:10.1029/2005JD007044, 2007. 